\title{
The Summer Asia-North America Teleconnection and its Modulation by ENSO in Community Atmosphere Model, Version 5 (CAM5)
}

Kelsey Malloy ( $\square$ kelsey.malloy@rsmas.miami.edu )

University of Miami Rosenstiel School of Marine and Atmospheric Science https://orcid.org/00000002-1989-7490

Ben P. Kirtman

University of Miami Rosenstiel School of Marine and Atmospheric Science

\section{Research Article}

Keywords: continental United States (CONUS), East Asian monsoon (EAM), Asia-North America (ANA), Community Atmospheric Model version 5 (CAM5), ENSO phases.

Posted Date: November 22nd, 2021

DOI: https://doi.org/10.21203/rs.3.rs-1062059/v1

License: (c) (i) This work is licensed under a Creative Commons Attribution 4.0 International License. Read Full License

Version of Record: A version of this preprint was published at Climate Dynamics on March 4th, 2022. See the published version at https://doi.org/10.1007/s00382-022-06205-4. 
The summer Asia-North America teleconnection and its modulation by ENSO in Community Atmosphere Model, version 5 (CAM5)

Kelsey Malloy ${ }^{1}$, Ben P. Kirtman ${ }^{1}$

${ }^{1}$ Rosenstiel School of Marine and Atmospheric Science, University of Miami, Miami, Florida

Corresponding author address:

Kelsey Malloy

kelsey.malloy@rsmas.miami.edu 
Seasonal forecasts of summer continental United States (CONUS) rainfall have relatively low skill, partly due to a lack of consensus about its sources of predictability. The East Asian 51 monsoon (EAM) can excite a cross-Pacific Rossby wave train, also known as the Asia-North 52 America (ANA) teleconnection. In this study, we analyze the ANA teleconnection in 53 observations and model simulations from the Community Atmospheric Model, version 5 54 (CAM5), comparing experiments with prescribed climatological SSTs and prescribed observed 55 SSTs. Observations indicate a statistically significant relationship between a strong EAM and 56 increased probability of positive precipitation anomalies over the U.S. west coast and the Plains-

57 Midwest. The ANA teleconnection and CONUS rainfall patterns are improved in the CAM5 58 experiment with prescribed observed SSTs, suggesting that SST variability is necessary to 59 simulate this teleconnection over CONUS. We find distinct ANA patterns between ENSO 60 phases, with the La Niña-related patterns in CAM5_obsSST disagreeing with observations. 61 Using linear steady-state quasi-geostrophic theory, we conclude that incorrect EAM forcing 62 location greatly contributed to CAM5 biases, and jet stream disparities explained the ENSO63 related biases. Finally, we compared EAM forcing experiments with different mean states using 64 a simple dry nonlinear atmospheric general circulation model. Overall, the ANA pattern over 65 CONUS and its modulation by ENSO forcing are well described by dry dynamics on seasonal66 to-interannual timescales, including the constructive (destructive) interference between El Niño 67 (La Niña) modulation and the ANA patterns over CONUS. 


\section{Introduction}

The agricultural sector, water resource managers, and other preparedness agencies desire monthly-to-seasonal rainfall forecasts for their decision-making, including for many vulnerable regions of the continental United States (CONUS), such as the western U.S. and Great Plains. However, there has been marginal success in providing reliable long-range forecasts of precipitation in the warm season (Becker et al. 2014; Slater et al. 2016; Hao et al. 2018; Malloy and Kirtman 2020), mostly due to relatively weak atmospheric flow as well as weaker signals from El Niño-Southern Oscillation (ENSO) and the Madden-Julian Oscillation (MJO; Trenberth et al. 1998; Zhou et al. 2012; Tian et al. 2017; Jha et al. 2019; Hu et al. 2020). For these reasons, there is amplified interest within the scientific community to understand causes of CONUS summer hydroclimate variability and its predictability.

Recent studies have indicated that quasi-stationary Rossby waves might be a key to summertime predictability, especially for climate extremes (Liu et al. 1998; Ciancarelli et al. 2014; Lopez et al. 2019; DeAngelis et al. 2020; Lee et al. 2011; Schubert et al. 2011; Zhao et al. 2018; Beverley et al. 2019; Mariotti et al. 2020; Jong et al. 2021). Rossby waves can be excited by remote sources, often guided by westerly jet streams as equivalent barotropic structures (Lau and Weng 2002; Lee et al. 2009; Schubert et al. 2011; Moon et al. 2013; Zhu and Li 2016; O'Reilly et al. 2018). These circumglobal patterns are a prominent mode of upper-level circulation variability (Ding and Wang, 2005; Ding et al. 2011; Weaver et al. 2016); in fact, Lee et al. (2011) estimated that up to $35 \%$ of the interannual variability in the mid-latitudes can be attributed to near-circumglobal teleconnections. The causes of quasi-stationary Rossby wave activity include distinct and joint influences from the Asian summer monsoon (ASM) and ENSO, among other possible forcing. 
The East Asian monsoon (EAM) is considered the northeastern branch of the ASM that

92 affects eastern China, Korea, and Japan (Ha et al. 2018). EAM precipitation and circulation is

93 typically out-of-phase with the western North Pacific monsoon (WNPM; Moon et al. 2013; Zhao

94 et al. 2015), another sub-system of the ASM located south of the EAM that affects southeast

95 Asia and the Philippines. Together, the EAM and WNPM comprise a northward-propagating rain

96 belt with variability on intraseasonal, seasonal, interannual, and interdecadal timescales (Wang et

97 al. 2001; Wang et al. 2008; Moon et al. 2013; Zhao et al. 2015; Lee and Wang 2016).

Because of its proximity to the East Asian jet, EAM heating is favorable for generating

99 Rossby wave responses (Lau and Weng 2002; Moon et al. 2013; Zhu and Li 2016; Zhao et al.

100 2018; Zhu and Li 2018). This upper-level wave pattern, the Asia-North America (ANA)

101 teleconnection, often traverses the North Pacific and reaches North America (Lau and Weng

102 2002; Zhu and Li 2016; Yang et al. 2020). Zhu and Li (2016) found that ANA is associated with

103 a northwest-southeast U.S. dipole of positive-negative rainfall anomalies. A series of AGCM

104 experiments in their study suggested that the EAM can force the ANA independent of ENSO.

105 There is a robust statistical and dynamical relationship between East Asian and North American

106 climate via this barotropic Rossby wave train (Wang et al. 2001; Moon et al. 2013; Zhao et al.

107 2018; Lopez et al. 2019; Yang et al. 2020), though influence is most evident in the Great Plains

108 and Midwest regions (Lopez et al. 2019).

The link between ENSO-forced North Pacific wave patterns and summer CONUS

110 hydroclimate is more complex. There is evidence that the warm phase of ENSO can excite the

111 Pacific-North America (PNA) teleconnection in the summer by itself (Schubert et al. 2002;

112 Pegion and Kumar 2010; Hu and Feng 2012; Zhu et al. 2013; Weaver et al. 2016), but results are

113 inconsistent. For example, Ciancarelli et al. (2014) showed that the influence of tropical Pacific 
114 SST forcing is prominent in the early summer months, whereas Weaver et al. (2009) suggested 115 influence peaks in the late summer months.

Rather, the relationship between ENSO and CONUS hydroclimate may be more indirect;

117 ENSO affects EAM variability and/or the mean state in which EAM forcing responses

118 propagate. On the seasonal-to-interannual timescale, studies indicate that transitioning or

119 developing ENSO phases impact East Asian jet variability (Ting and Wang 1997; Du et al. 2016)

120 and/or EAM and WNPM precipitation variability (Wang et al. 2001; Wang et al. 2008; Wu et al.

121 2009; Zhao et al. 2015; Jong et al. 2021). Ding et al. (2011) found that ENSO can modulate the

122 strength of the EAM, altering North Pacific wave patterns. On the intraseasonal timescale, the

123 phase of ENSO can impact the period of the northward-propagating mode (Liu et al. 2016).

124 Finally, long-range predictability from EAM-related responses may come from ENSO (Lee et al.

125 2011; Liu et al. 2019; Zhou et al. 2020). Potential predictability of the EAM and its

126 teleconnections have been linked to interdecadal ENSO variability, i.e. there are decades when

127 ENSO has a greater influence on the EAM (Song and Zhou 2015; Zhu and Li 2018; Li et al. 128 2019).

There are several studies on the assessment of summer teleconnections and associated North American hydroclimate in current global climate models, many of which demonstrate that 131 SST variability is vital for representing atmospheric circulation responses over CONUS (Weaver 132 et al. 2009; Hu and Feng 2012; Burgman and Jang 2015). Sheffield et al. (2013) found that 133 models in Coupled Model Intercomparison Project, version 5 (CMIP5) could not simulate 134 CONUS summer teleconnections and mechanisms related to its forced variability from SST 135 anomalies well. More specifically, North Pacific Rossby wave patterns related to a transitioning 136 Niño-to-Niña and western Pacific heating were weaker and inconsistent in Community 
Atmosphere Model, version 5 (CAM5) without air-sea interaction (Jong et al. 2021). Air-sea interaction improves EAM precipitation-SST connection (Liu et al. 2019; et al. Islam 2013; Islam and Tang 2017), though there is realistic depiction of monsoonal precipitation climatology and interannual variability in both CAM5 (Islam et al. 2013; Islam and Tang 2017) and CMIP5 (Sperber et al. 2013) overall.

Despite the perceived importance of Pacific SST variability, idealized atmospheric model experiments with a prescribed summertime climatological background state from Zhu and Li (2016) and Lopez et al. (2019) also produced the observed ANA pattern. In addition, there are few studies that explicitly assess the ANA teleconnection in global climate models, including the evaluation of predictability from prescribed SST variability. Therefore, our paper will address the lack of understanding about the ANA teleconnection in observations as well as in a state-ofthe-art climate model. Using a simple framework, we isolated the EAM-forced and ENSOmodulated circulation responses and precipitation impacts over CONUS. Due to emergent literature on the important role of the mean or background state in climate models and skill in teleconnection representation and prediction (Henderson et al. 2017; Kim et al. 2020; Wang et al. 2020), we diagnosed the roles of mean state and forcing in producing the ANA patterns and related model biases on the long-range timescale.

Section 2 contains the description of the datasets, model experiments, and analysis methods for the study. Results begin in Section 3, with the comparison of the ANA pattern between observations and CAM5, including how ENSO influences this pattern. In Section 4, we explain the circulation responses to EAM-related forcing and ENSO modulation as well as model discrepancies using linear QG theory and additional simple dry AGCM experiments. 
159 Finally, a summary and discussion of these results - including any complementary studies,

160 limitations, and suggested future work - are given in Section 5.

\section{2. Data and Methods}

162 a. Observational datasets

All observations are monthly values in the June-July-August (JJA) season for 1979-2019.

164 Zonal wind, meridional wind, geopotential height, temperature, and divergence data were

165 obtained from the European Centre for Medium-Range Weather Forecasts (ECMWF) fifth-

166 generation reanalysis (ERA5), which is provided on a $0.25^{\circ}$ latitude/longitude grid (Hersbach et

167 al. 2020). Precipitation data were taken from Climate Prediction Center (CPC) Merged Analysis

168 of Precipitation (CMAP), which combines satellite and gauge data on a global $2.5^{\circ}$

169 latitude/longitude grid (Xie and Arkin 1997). Global SST data were taken from the Extended

170 Reconstructed Sea Surface Temperature, version 5 (ERSST-5), which is provided on a $2^{\circ}$

171 latitude/longitude grid (Huang et al. 2017).

172 b. CAM5 experiments

173 CAM5 is a global circulation model (GCM) and the atmospheric component of the

174 Community Earth System Model (CESM), developed by the National Center for Atmospheric

175 Research (NCAR; Neale et al., 2010). Atmosphere-only 30-year simulations were conducted

176 with prescribed global SSTs on an ocean data model. We analyzed monthly JJA output data with

177 a resolution of $0.47^{\circ}$ latitude by $0.63^{\circ}$ longitude and 30 vertical levels.

178 To investigate the role of SST variability on the ANA teleconnection, we performed two

179 experiments: one simulation with prescribed climatological SSTs (hereby referred to as

180 CAM5_climoSST), and the other simulation with prescribed observed SSTs (CAM5_obsSST).

181 The CAM5_obsSST experiment used the 1972-2001 period for SST data. This introduces global 
182 SST variability (e.g. ENSO), compared to the CAM5_climoSST experiment, where the

183 prescribed time-mean SST data filters out this variability.

184

185

186

187

188

189

190

191

192

\section{d. Linear steady-state quasi-geostrophic solutions}

We explored the steady-state quasi-geostrophic (QG) linearity of the response to prescribed divergence and mean state. This method starts with the linear QG vorticity equation:

$$
\frac{\partial \zeta_{g}}{\partial t}+v_{g} \cdot \nabla\left(\zeta_{g}+f\right)=-f_{0} \nabla \cdot v
$$

where $\zeta_{g}$ is the geostrophic vorticity, $v_{g}$ is the geostrophic velocity, $\mathrm{f}$ is the Coriolis parameter, $f_{0}$ is the Coriolis constant, and $\nabla \cdot v$ is the divergence. Focusing on the steady-state response, using the mid-latitude beta-plane approximation $\left(\mathrm{f}=\mathrm{f}_{0}+\beta \mathrm{v}\right)$, and viewing the divergence term on the right-hand side as forcing (denoted as F), the equation becomes:

$$
u_{g} \frac{\partial \zeta_{g}}{\partial x}+\beta v_{g}=F
$$

The first term on the left-hand side is the advection of geostrophic relative vorticity by the geostrophic zonal wind, and the second term on the left-hand side is the advection of planetary vorticity by the geostrophic meridional wind. These terms "compete" to balance the divergence forcing term on the right-hand side. Finally, we linearize the equation about a prescribed time mean geostrophic zonal wind and solve for the geostrophic meridional wind via a fixed-point iteration. The calculated meridional wind field is converted to a geopotential height field.

In using this equation, we are interested in how differences in the mean state, $\overline{u_{g}}$ (hereby referred to as $\bar{U}$ ) and EAM-related divergence forcing, F, alter the linear QG response, which is the ANA pattern in this study. We specified $\bar{U}$ as the 250-hPa zonal wind (U250) climatology and the divergence forcing $(\mathrm{F})$ as the strong - weak EAM 250-hPa divergence (DIV250) 
203

204

205

206

207

208

209

210

211

212

213

214

215

216

217

218

219

220

221

222

223

224

225

anomaly composite. These values are taken from observations, CAM5_climoSST, or

CAM5_obsSST. We also considered $\bar{U}$ and $\mathrm{F}$ that are conditioned on ENSO state (Niño or Niña)

to assess the importance of indirect ENSO modulation of responses and biases. Finally, we tested direct ENSO modulation by adding tropical Pacific El Niño or La Niña divergence forcing and subtracting that response from response with only EAM forcing.

\section{c. Dry AGCM experiments}

To isolate the dry atmospheric processes, we also tested EAM forcing with a dry, baroclinic, nonlinear AGCM. This is a spectral model with Rhomboidal truncation at R42, which equates to a $1.7^{\circ}$ latitude by $2.8^{\circ}$ longitude grid, and it has 26 vertical levels. The model solves the full primitive equations of divergence, vorticity, temperature and surface pressure. The AGCM is adapted from Brenner et al. (1984) to remove moist processes. Newtonian cooling is specified throughout the troposphere with enhanced damping near the surface. Rayleigh friction is specified at the lower levels and mimic realistic land-sea frictional contrasts. Versions of this dry AGCM have been used in Kirtman et al. (2001) and is described in detail in Brenner et al. (1984). This simple, idealized model is used for evaluating the large-scale teleconnections, primarily quasi-stationary wave activity and dry dynamic processes.

The model requires a mean state as input, with an option to add heating forcing. The JJA surface temperature climatology is input as mean state for the model. Climatology was calculated from ERA5, CAM5_climoSST, and CAM5_obsSST data and interpolated to the model's grid. Each experiment with the respective mean state was integrated forward for 900 days, but analysis excluded the spin-up period of 100 days. EAM-forced responses are calculated by performing an experiment with EAM heating and then performing an experiment without EAM heating, both in the same mean state, and subtracting the difference. The EAM-forced 
226 experiments apply a constant diabatic heating via Gaussian bubble with a maximum of $2 \mathrm{~K}^{\text {day }}{ }^{-1}$

227 centered at $30^{\circ} \mathrm{N}, 120^{\circ} \mathrm{E}$ and $300 \mathrm{hPa}$ (see Supp. Fig. 1), similar to Zhu and Li (2016). Note that

228 we also tested strong - weak EAM by running an experiment with positive heating forcing and

229 an experiment with negative heating (cooling) in EAM location. Because patterns were similar,

230 they have been excluded for the sake of brevity.

231 Finally, we address both indirect and direct ENSO modulation to the EAM-forced

232 response as we did with the linear QG solutions: Indirect ENSO modulation was assessed by

233 adjusting the observed and CAM5_obsSST mean state based on surface temperature climatology

234 composited during El Niño or La Niña months, and direct ENSO modulation was assessed by

235 running experiments with both ENSO-related forcing and EAM forcing and subtracting that

236 response by the original EAM-forced response. El Niño heating/La Niña cooling forcing location

237 was chosen based on El Niño - La Niña divergence anomaly composites. A list and description

238 of the experiments and their differences in purpose and setup can be found in Table 1.

239 e. EAM and ENSO definitions

240 The EAM index was defined by upper-level circulation as in Zhao et al. (2015):

$241 \operatorname{Std}\left[\mathrm{U} 200\left(2.5-10^{\circ} \mathrm{N}, 105-140^{\circ} \mathrm{E}\right)-\mathrm{U} 200\left(17.5-22.5^{\circ} \mathrm{N}, 105-140^{\circ} \mathrm{E}\right)+\mathrm{U} 200\left(30-37.5^{\circ} \mathrm{N}, 105-\right.\right.$

$\left.\left.242140^{\circ} \mathrm{E}\right)\right]$, where $\mathrm{U} 200$ is the $200-\mathrm{hPa}$ zonal wind averaged within the domain outlined in the 243 parentheses, and Std indicates a standardization of the timeseries of the index. Strong and weak

244 EAM events are determined by the upper and lower terciles of the index, respectively. We chose

245 this index because it characterizes the distinct EAM and WNPM precipitation anomalies, 246 captures multiple timescales of variability, and has been linked to ENSO (Zhao et al. 2015).

247 We categorized ENSO events using the Niño3.4, defined as $\left[\mathrm{T}^{*}\left(5^{\circ} \mathrm{S}-5^{\circ} \mathrm{N}, 170-120^{\circ} \mathrm{W}\right)\right]$,

248 where $\mathrm{T}^{*}$ denotes SST anomalies. Niño events were defined by a monthly Niño3.4 index greater 
249 or equal to $0.5^{\circ} \mathrm{C}$, and Niña events were defined by a monthly Niño3.4 index less than or equal to

$250 \quad 0.5^{\circ} \mathrm{C}$. Otherwise, the ENSO event was considered neutral.

251 3. The ANA Teleconnection in Observations and CAM5

252 a. EAM-related precipitation and circulation patterns

The ANA teleconnection is the bridge between EAM rainfall and CONUS rainfall. First,

254 we established this relationship using difference composites, calculated by subtracting the

255 averaged precipitation anomalies during strong EAM events by the averaged precipitation

256 anomalies during weak EAM events and standardizing the difference. The strong - weak EAM

257 precipitation standardized anomalies are seen in Fig. 1 (left column). In observations (top left),

258 the EAM structure is established, with significant positive rainfall anomalies within the $25-35^{\circ} \mathrm{N}$

259 latitudinal belt and stretched over the western and central North Pacific. Negative rainfall

260 anomalies are located south and north of the EAM rainfall belt as a part of the full monsoonal

261 circulation. Over CONUS, there are two regions that have statistically significant EAM-related

262 precipitation anomalies: the west coast and Plains-Midwest regions (corresponding purple and

263 magenta boxes). To analyze further, we found the kernel density estimation (KDE) of the

264 standardized precipitation anomalies at each month and grid point within the box for the strong

265 EAM events and weak EAM events (right columns). The distribution of strong EAM anomalies

266 (red) is shifted right from the weak EAM anomalies (blue), indicating that a strong EAM is

267 associated with a higher probability of wet anomalies in these regions. The CONUS difference

268 composite pattern, though not statistically significant everywhere, is analogous to the northwest-

269 southeast rainfall dipole from Zhu and Li (2016).

Generally, the CAM5_climoSST standardized precipitation anomaly difference

271 composite (Fig. 1, middle left) is similar to the observed over the EAM region. Over CONUS, 
272 the associated precipitation anomalies over the west coast are positive, but anomalies over the

273 Plains-Midwest are negative, unlike observations. The KDEs (middle right) corroborate this

274 result: there is a higher probability of wet anomalies during a strong EAM over the west coast,

275 most apparent at the right tail, and there is decreased probability of wet anomalies over the

276 Plains-Midwest during strong EAM events.

277 The precipitation anomaly pattern is more comparable to the observations in the

278 CAM5_obsSST standardized precipitation difference composite (Fig. 1, bottom left). The

279 structure of the anomalies for the entire monsoonal system is better represented. The CONUS

280 precipitation anomaly pattern is improved, particularly over the Plains-Midwest, though these

281 wet anomalies also extend to the southern Plains. However, there are dry anomalies in the

282 eastern North Pacific and southern west coast that are not present in observations. The KDEs for

283 the west coast indicate a minor shift in the distribution of precipitation anomalies to the right.

284 However, there is not a clear distribution shift over the Plains-Midwest. This may suggest that

285 the EAM-CONUS rainfall relationship is more affected by local processes in the model. Overall,

286 CAM5_obsSST is able to capture the rainfall pattern, and we attempt to address biases or

287 discrepancies in the remainder of the study by interpreting Rossby wave responses.

On this timescale of interest, the anomalous zonally-asymmetric component of the

289 circulation, stationary eddies, controls the pattern of anomalous moisture transport and rainfall

290 (Liu et al. 1998). Fig. 2 shows the zonally-asymmetric component of the strong - weak EAM

291 Z250 anomaly difference composite $\left(\overline{Z 250^{\prime *}}\right)$. In observations (top), a strong EAM is associated

292 with a wave train pattern oriented meridionally over East Asia and Siberia. An anomalous ridge

293 stretches from the EAM region to the North American coast, an anomalous trough is found off

294 the coast of Baja California/U.S. southwest and across the Gulf of Mexico, and an anomalous 
295 ridge is centered over Quebec/Hudson Bay. This pattern is weak over North America, but it is generally in agreement with previous studies that showed that anomalous troughs over western U.S. are important to identify southerly winds and moisture transport into CONUS, fueling 298 precipitation events (Mallakpour and Villarini 2016; Malloy and Kirtman 2020). Unlike observations, the $\overline{Z 250^{\prime *}}$ difference composite pattern from CAM5_climoSST has more of a zonal wave train structure from the EAM region to North America, and, over North America, the west-east pattern is opposite to observations. The $\overline{Z 250^{\prime}}$ difference composite pattern from CAM5_obsSST has a noticeably improved representation of the teleconnection over North America. This also dynamically explains the better comparison of the standardized precipitation anomaly differences between observations and CAM5_obsSST from Fig. 1. In general, including prescribed global SST variability in CAM5 improved the representation of the

306 ANA pattern and its associated precipitation patterns over North America. Even in the EAM 307 region, the local stationary wave pattern in the observations is not particularly well captured by 308 the model, somewhat surprisingly, although arguably better with observed SST forcing. b. EAM-related patterns separated by ENSO phase

On seasonal-to-interannual scales, ENSO has been found to have an influence on the 311 EAM response (Ding et al. 2011); therefore, conditioning the EAM-related pattern on ENSO 312 phases for observations and CAM5_obsSST may reveal different impacts downstream. The observed conditioned strong - weak EAM composites of standardized precipitation 314 anomalies and $\overline{{Z 250^{\prime}}^{*}}$ validate that ENSO phase is important for understanding CONUS 315 impacts. Fig. 3 shows the classification of the difference composites from Fig. 1 and 2 into 316 ENSO phases by finding the strong - weak EAM during El Niño (top row), neutral ENSO 317 (middle row), and La Niña (bottom row) months. Over the Plains-Midwest, EAM-related 
318 precipitation anomalies (left column) during El Niño are more robust than during neutral ENSO

319 or La Niña. The west coast anomalies are less sensitive to ENSO phase, showing statistically

320 significant wet anomalies during the neutral phase. The largest differences in $\overline{Z 250^{\prime *}}$ are over the

321 eastern North Pacific and North America (right column), with La Niña being associated with an

322 anomalous ridge over most of Canada and the Pacific Northwest. By examining the KDEs

323 (middle columns) of the standardized precipitation anomalies, during La Niña, the Plains-

324 Midwest has a greater probability of dry anomalies during a strong EAM.

325 The weaknesses in the model capturing the observed EAM-CONUS teleconnections are 326 amplified when stratifying by ENSO phase. As seen in Fig. 4, there are wet anomalies over the 327 west coast and Plains-Midwest during neutral ENSO months (left middle), further established by 328 the slight shift in distribution for strong EAM events. The west coast precipitation anomalies are 329 contingent on ENSO phase in CAM5_obsSST: during El Niño (top left), there is a north-south 330 pattern of wet-dry anomalies and no discernible difference in the KDEs (top right) between 331 strong and weak EAM months, and, during La Niña (bottom left), there is a greater probability of 332 wet anomalies overall. The $\overline{Z 250^{\prime}}$ patterns over North America are also dissimilar: during El 333 Niño, the $\overline{Z 250^{\prime}} *$ difference composite is not statistically significant over North America (top 334 right), and, during La Niña, there is a cross-Pacific wave train response, with an anomalous 335 trough over western North America and an anomalous ridge over eastern North America (bottom 336 right). This explains the extreme positive precipitation anomalies in the composites (bottom left) 337 and increased probability of positive precipitation anomalies over the Plains-Midwest seen in the 338 KDE shifts. Overall, the ENSO-modulated ANA teleconnection is not well represented in 339 CAM5_obsSST, especially during La Niña. 
We note that one limitation of this experimental design is that the observations and model

341

342 include different time periods: 1979-2019 for observations and 1972-2001 for CAM5_obsSST. However, we performed the same analysis for the overlap period - 1979-2001 - and found that results overall were similar and only subtle differences exist (cf. Supp. Figs. 2 and 3). Therefore, the different time periods between model and observations does not explain the discrepancies.

The ANA teleconnection was better represented in CAM5_obsSST, the experiment that simulated global SST variability. Yet, the distinct patterns from the ENSO phases were unlike even opposite to - the observations. This motivates a need to understand the EAM-forced and ENSO-influenced responses. What are the roles of the mean state and divergence forcing, and why does the model fail to capture the observed relationships?

\section{The Roles of Mean State and Forcing}

\section{a. Steady-state linear $Q G$ solution results}

The linear QG analysis presented here is examining the extent to which the EAM-

CONUS ANA teleconnection can be understood in this simple framework. Essentially, the extent to which the linear QG model captures the CONUS component of the teleconnection can be used to understand, at least in part, why CAM5 fails and further bolsters the simple interpretation of the observational results.

As described in Section 2, the steady-state linear QG solution to EAM forcing in the midlatitudes depends on the divergence forcing $(\mathrm{F})$ structure and a mean state $(\bar{U})$, both of which are different between the observations, CAM5_climoSST experiment, and CAM5_obsSST experiment. Fig. 5 summarizes the different linear QG Z250 responses and attempts to isolate the $\bar{U}$ and F "contribution" to the pattern. The observed response can be seen in the top panel: when inputting U250 climatology as $\bar{U}$ and strong - weak EAM DIV250 anomaly composite over 
363 EAM region as $\mathrm{F}$, the solution is a meridionally oriented $\mathrm{Z} 250$ pattern over the EAM region and 364 a zonally oriented wave train over the North Pacific and North America. While not perfect, there 365 are many similarities to the ANA pattern from Fig. 2 (top), particularly the response over the 366 EAM region and generally over the eastern North Pacific and North America. The CAM5_climoSST response (Fig. 5, left middle) - obtained by inputting its separate 368 U250 climatology and DIV250 anomaly composite - is much different. The mid-latitude 369 response matches the overall pattern from Fig. 2 (middle); the ANA teleconnection from 370 CAM5_climoSST can be described by the steady-state linear QG response the EAM forcing. 371 Interestingly, the CAM5_obsSST response (left bottom) looks identical to the CAM5_climoSST 372 response despite the stark differences over CONUS seen in Fig. 2.

373 We next fixed $\mathrm{F}$ as the divergence anomalies from observations (Fig. 5, middle column), 374 keeping $\bar{U}$ as corresponding to CAM5_climoSST or CAM5_obsSST, which improves the ANA 375 pattern overall. The response over the EAM region improves, and the response with the $\bar{U}$ from 376 CAM5_obsSST (middle bottom) looks more like its EAM-related pattern from Fig. 2 (bottom), 377 especially over the mid-latitude Pacific, Alaska, and southwest U.S. This suggests that F greatly 378 influences the structure of the ANA pattern, and the F biases in CAM5 are limiting its 379 representation of the pattern. In addition, the contrasts in the $\mathrm{Z} 250$ response via $\bar{U}$ differences 380 between CAM5_climoSST and CAM5_obsSST are highlighted. Though subtle, the different $\bar{U}$ 381 (jet stream climatologies) in these CAM5 experiment can perhaps explain some aspect of the 382 different Z250 responses over the North Pacific. We also fixed $\bar{U}$ as the U250 climatology from observations (Fig. 5, right column) and 384 kept F as corresponding to CAM5_climoSST or CAM5_obsSST, confirming former findings. 385 The structure of these responses looks similar to the CAM5 responses without the fixed $\bar{U}$ (left 
middle and left bottom), and dissimilar to the observed response (top), further validating the importance of improving the EAM-related divergence forcing, F, to correct the ANA pattern and associated impacts over CONUS.

In brief, the linear QG solutions captured many aspects of the observed ANA teleconnection (cf. Fig. 5 vs. Fig. 2). The misrepresentation of the ANA teleconnection in CAM5 is greatly influenced by the CAM5 biases in the EAM forcing $(F)$. Differences between the two CAM5 simulations (CAM5_climoSST vs. CAM5_obsSST) are very subtle and not well explained by this linear QG framework.

To understand the indirect ENSO influence on the ANA pattern in observations and the CAM5_obsSST simulation, F was conditioned on ENSO phase before solving for the Z250 response, i.e. F was input as the strong - weak EAM DIV250 anomaly during El Niño or La Niña. In Fig. 6, for the observed Z250 EAM-forced responses (left column) during El Niño (top) and La Niña (bottom), there is little difference. This is also true for the CAM5_obsSST responses (right column). ENSO's influence on the location/structure of EAM divergence forcing does not modulate the ANA pattern. Nevertheless, the disparities between the observed (left column) and CAM5_obsSST (right column) responses can still be described by the differences in the F location/structure, once again.

$\bar{U}$ was also conditioned on ENSO phase, i.e. $\bar{U}$ was taken as the U250 composite during El Niño or La Niña, and stark differences between the responses with El Niño-related $\bar{U}$ and La Niña-related $\bar{U}$ are discerned in Fig. 7. In observations, the Z250 response with El Niño-related $\bar{U}$ (top left) is more amplified and has an eastward-shifted structure. Interestingly, the canonical El Niño pattern (typically linked to winter) is observed over North America, with an anomalous trough over southern CONUS and an anomalous ridge north of it. In contrast, the response with 
409

410

the La Niña-related $\bar{U}$ (bottom left) has an opposite pattern, closer to the response not conditioned on ENSO in Fig. 5 (top).

The CAM5_obsSST solutions reveal the limitations of the model mean state during ENSO. The response with the El Niño-related $\bar{U}$ (Fig. 7, top right), like the observed response, has a wave pattern over the North Pacific, with an anomalous trough over the eastern North Pacific and anomalous ridge over the high-latitudes of North America. The wavelength of this pattern is shorter with the $\bar{U}$ from CAM5_obsSST, and it does not include the anomalous trough over southern CONUS, but there are many parallels. Conversely, the response with the La Niñarelated $\bar{U}$ has very little resemblance to the La Niña-related response from observations.

In short, conditioning the $\bar{U}$ on ENSO does seem to explain (1) the variability in the ANA pattern and (2) large model biases in CAM5_obsSST during La Niña months. However, we note that these responses are not comparable to Figs. 3 and 4 (top, bottom), particularly over CONUS.

Direct ENSO modulation is most apparent over CONUS, seen in Fig. 8. In observations, El Niño modulation (top left) leads to an amplification of the EAM-forced response over CONUS (cf. Fig 5, top left) and La Niña modulation (bottom left) leads to a weakening. Although the ENSO forcing in the tropical Pacific is much stronger in CAM5_obsSST than observations (purple and green contours), the CAM5_obsSST solutions for El Niño modulation (top right) and La Niña modulation (bottom right) are weaker. There is little difference between ENSO phases over CONUS, suggesting that CAM5_obsSST ENSO-related mean state differences are not substantial enough to impact indirect ENSO modulation in CAM5.

Despite the usefulness in the linear QG solutions and framework, there are aspects of the ANA teleconnection, such as the subtropical Pacific response, not captured. In addition, this framework does not address concerns about variability of this response; differences in mean state 
432 between observations and CAM5 may influence the robustness of the EAM-forced response.

433 Finally, while we added direct ENSO-related divergence forcing to this model to assess direct

434 modulation, it is possible that their interaction is nonlinear. For these reasons, we utilize the dry

435 nonlinear AGCM.

436 b. Dry nonlinear AGCM experiment results

437 The dry, nonlinear AGCM can test the sensitivity of responses with different mean states 438 while also determining the robustness of the EAM-forced circulation response. Robustness is 439 measured by calculating the 90-day moving mean standard deviation $(\sigma)$ of the response, and 440 dividing the responses according to this moving mean standard deviation $\sigma$. The following 441 results are from experiments where the heating forcing location was based on the observed 442 EAM-related divergence anomalies (Fig. 5, top left). Results for the EAM-forced experiments 443 with the mean states from CAM5 when the heating forcing is $10^{\circ}$ eastward shift (based on Fig. 5, 444 middle and bottom left) are provided in Supp. Fig. 4, though the findings are similar. In Fig. 9, when the observational climatology was input as the mean state (top row), the $446 \overline{Z 250}^{*}$ response (left column) includes a robust elongated anomalous ridge over the North 447 Pacific and anomalous trough centered over the southwestern U.S., indicated by the >+1 $\sigma$ and <$4481 \sigma$ anomalies, respectively. By comparing to Fig. 2 (top), it is apparent that the dry atmospheric 449 dynamics in this AGCM can effectively simulate the observed ANA teleconnection. Because this 450 is a dry model, we can consider the time-mean DIV250 response (right column) as a proxy for 451 large-scale precipitation patterns associated with the heating forcing. The observed DIV250 452 response also corresponds with EAM-related patterns from Fig. 1 (top left). There is upper-level 453 divergence over the western coast, central U.S., and regions of Quebec, which are dynamically 454 linked to the wet anomalies. Additionally, there is upper-level convergence over 
Alberta/Northwest Territories, southwest U.S., and the eastern coast, dynamically linked to dry anomalies. However, this response is relatively weak as $\sigma$ values are low; this suggests that large-scale precipitation patterns due to EAM heating forcing are subject to significant variability on the seasonal-to-interannual timescales. In fact, differences/modulation of DIV250 responses are not discernible and not robust (Figs. 10-13, right column); therefore, we concentrate on $\overline{Z 250}^{*}$ responses/differences for remainder of results.

Over East Asia and North Pacific, the dry AGCM responses when the CAM5_climoSST and CAM5_obsSST experiment climatologies were input as the mean state are well represented (Fig. 9, middle and bottom row). The $\overline{Z 250}^{*}$ response is a more zonal wave pattern, corresponding well to Fig. 2 (middle and bottom). However, the strong anomalous trough centered over southern U.S. and northern Mexico in the dry AGCM is unlike the composite pattern in Fig. 2. The DIV250 responses are not significantly different from the experiment with the mean state from observations. Overall, while the dry AGCM responses can explain CAM5 ANA patterns over the North Pacific well, there are discrepancies over North America between the dry AGCM responses and composite patterns that suggest additional processes are likely to be important. Other sources of forcing (e.g. ENSO) and/or land-atmosphere feedbacks may significantly contribute in simulating the ANA teleconnection in CAM5 experiments.

The dry AGCM response differences in Figs. 10 and 11 suggest that El Niño- or La Niñarelated mean state differences alter the responses, confirming the steady-state linear QG solution results. The difference in dry $\operatorname{AGCM} \overline{Z 250} *$ response with the observational El Niño-composited climatology as the mean state (Fig. 10, top left) has an anomalous ridge over high-latitude East Asia, an anomalous trough centered over the Bering Sea, an anomalous ridge over the Gulf of Alaska, and an anomalous trough over central North America. This is opposed to the response 
478 with the La Niña-composited climatology as the mean state (Fig. 11, top left), which reveals an

479 opposite pattern. By comparing with the conditional composites from Figs. 3 (right column), we

480 find that the indirect modulation with the dry AGCM simulates ENSO-related patterns overall

481 over North America, but not over East Asia and the North Pacific.

482

The responses with the CAM5_obsSST Niño- and Niña-composited climatologies (Figs.

48310 and 11, bottom left) are very similar to each other, just as with the linear QG solutions.

484 ENSO-related mean state differences are not strong in CAM5, reducing indirect ENSO

485 modulation. By comparing with the conditional composites from Fig. 4 (right column), we

486 observe that the dry AGCM does not capture the ENSO-related patterns from CAM5 well

487 overall, but there is somewhat more of a zonally oriented trough-ridge pattern over CONUS

488 associated with the response with the La Niña-composited climatology, as in Fig. 4 (bottom

489 right). In general, indirect ENSO modulation may not be sufficient in describing the ENSO-

490 related ANA patterns in this dry AGCM, especially over the North Pacific and for patterns from

491 CAM5_obsSST.

We effectively extract direct ENSO modulation, seen in Figs. 12 and 13. Note that these

493 should be interpreted as only the ENSO-modulated portion of the response, not the total EAM-

494 and ENSO-forced response. The El Niño-modulated $\overline{Z 250}^{*}$ with the observational mean state

495 (Fig. 12, top left) shows a band of negative anomalies stretched over the subtropical Pacific,

496 which would weaken the EAM-forced elongated North Pacific ridge and strengthen the trough

497 over western CONUS (cf. Fig 9, top). In addition, there are positive anomalies over Alaska and

498 central-eastern CONUS. Collectively, this results suggests that El Niño promotes strengthening

499 of the west-east trough-ridge pattern, or constructive interference with the ANA pattern, over

500 CONUS, influencing enhanced precipitation over the Plains-Midwest (cf. Figs. 3, top left). 
501 Conversely, the La Niña-modulated $\overline{Z 250}^{*}$ with the observational mean state (Fig. 13, top left)

502 shows positive anomalies in the subtropical Pacific and western CONUS. The pattern over North

503 America is opposite to El Niño-modulated $\overline{Z 250}^{*}$, suggesting destructive interference with the

504 EAM-forced trough over western CONUS and explaining the decreased precipitation over the

505 Plains-Midwest during La Niña.

506 El Niño- and La Niña-modulated $\overline{Z 250}^{*}$ with the CAM5_obsSST mean state (Figs. 12

507 and 13, bottom left) have similar destructive and constructive interference of ANA pattern, 508 respectively, over the subtropical Pacific, as in the results with the observational mean state.

509 However, there is an anomalous ridge centered over CONUS in both the El Niño- and La Niña-

510 modulated $\overline{Z 250}{ }^{*}$ patterns, not aligning with observations nor explaining the ENSO-related

511 patterns from Fig. 4. Again, CONUS patterns in the dry AGCM with the CAM5_obsSST mean

512 state are not simulated well, perhaps emphasizing the differences in the important processes

513 behind the ANA pattern in observations and CAM5.

514 4. Summary and Discussion

515 Summer CONUS rainfall remains a forecast challenge. Understanding rainfall variability

516 and its links with quasi-persistent features, e.g. monsoons and SST anomalies, is imperative for

517 long-range forecasting. In this study, we established the statistical and dynamical relationship

518 between the EAM and CONUS precipitation and circulation anomaly patterns, the ANA

519 teleconnection, which impacts the U.S. west coast and Plains-Midwest regions (Figs. 1 and 2).

520 This confirmed Zhu and Li (2016) study's ANA rainfall pattern and the many studies that have

521 linked Plains-Midwest climate to EAM activity (Lopez et al. 2019), but the link between the

522 EAM and U.S. west coast precipitation is relatively novel. We compared the ANA pattern from

523 observations to its representation in a state-of-the-art atmospheric model, CAM5, where one 
524 experiment prescribed global climatological SSTs (CAM5_climoSST), and the other prescribed

525 global observed SSTs (CAM5_obsSST). The ANA patterns from the CAM5_obsSST experiment

526 were more similar to observations, suggesting that SST variability is important for simulating

527 this teleconnection, although some notable difference between CAM5_obsSST and the

528 observations were identified.

529 Because ENSO has an established influence on the EAM (Wang et al. 2001; Wang et al.

530 2008; Ding et al. 2011), we investigated the effect of ENSO's modulation on the ANA

531 teleconnection in observations and CAM5_obsSST (Figs. 3 and 4). The ANA patterns did

532 depend on ENSO phase over the Plains-Midwest region. However, representation of the ENSO-

533 modulated ANA patterns in CAM5_obsSST was limited; in fact, Niña-related ANA patterns

534 over the Plains-Midwest between observations and CAM5_obsSST were of opposite sign (dry

535 vs. wet anomalies, respectively).

536 Next, we used steady-state linear QG solution framework and a dry nonlinear AGCM to 537 diagnose to what extent the observations and the CAM5 simulations can be understood in terms 538 in this simplified framework as well as how much of the ANA teleconnection is due to nonlinear 539 processes. We summarize the results from this section as follows:

540 1. CAM5 limitations in representing the ANA pattern are due to CAM5 biases in the EAM 541 forcing location/structure (Figs. 5-8).

542 2. Conditioning the mean state on ENSO generates distinctive ANA patterns. The biases in 543 the ENSO-related mean state in CAM5_obsSST at least partly describes the erroneous 544 representation of the La Niña-related ANA teleconnection in CAM5_obsSST (Fig. 7).

545 3. Nonlinear, dry atmospheric dynamics is essential for producing the EAM-forced pattern 546 (cf. Fig 9, top and Fig. 2, top), particularly over the subtropics. 
4. Both indirect ENSO modulation and direct ENSO modulation are important for simulating details of the ANA pattern over CONUS (Figs. 8, 12 and 13). Generally, constructive (destructive) interference of El Niño (La Niña) patterns with the ANA pattern over CONUS explains enhanced (weakened) precipitation signals, particularly over the Plains-Midwest, which is reproduced well in both the linear QG solutions and nonlinear dry AGCM.

These results complement previous studies that explored teleconnection sensitivity to mean state (Henderson et al. 2017; Kim et al. 2020; Wang et al. 2020); model mean state, especially relating to jet stream strength and location, is essential for simulating correct Rossby wave responses and downstream impacts (O’Reilly et al. 2018).

Not all features of the ANA pattern nor the CAM5 biases were simulated/explained sufficiently with the linear QG model nor the dry AGCM (e.g. discrepancies over CONUS patterns between the dry AGCM responses with CAM5 mean states cf. Figs. 9-13 and CAM5 ANA pattern over CONUS in Figs. 2 and 4). Neither model has land-moisture feedbacks, which are likely key in simulating the combined EAM and ENSO influence. Generally, summertime predictability has been linked to soil moisture and atmosphere-land processes (Dirmeyer et al. 2003; Koster et al. 2006; Schubert et al. 2008; Burgman and Jang 2015; Jong et al. 2021); therefore, there should be more analysis done on specific connections between ANA-related rainfall and atmosphere-land coupling.

Future studies should consider additional sources of SST variability besides ENSO. Previous studies have suggested that North Atlantic SST variability is vital for understanding CONUS hydroclimate (Schubert et al. 2008; Weaver et al. 2009; Malloy and Kirtman 2020). Extratropical Pacific SST variability (e.g. Pacific Decadal Oscillation) influences both ENSO 
570 events and mid-latitude Rossby wave propagation on the interdecadal timescale (Lee et al. 2011;

571 Zhu et al. 2013; Burgman and Jang 2015; Song and Zhao 2015). Indian Ocean SST variability,

572 including the Indian Ocean Dipole (IOD), interacts with both ENSO and ASM variability (Islam

573 et al. 2013; Du et al. 2016; Lee and Wang 2016).

574 The study's focus was on contemporary, monthly-mean ENSO modulation of the ANA

575 teleconnection, but the transitional, slowly evolving aspects of ENSO-EAM links (e.g. post-peak

576 Niño effects) might also be important (Weaver et al. 2016; Li et al. 2019). ENSO variability on

577 the interdecadal timescale (Wu et al. 2009; Zhu and Li 2018) may change how it modulates the

578 ANA pattern or robustness/predictability of responses.

579 Both complex AGCMs and simple dry AGCMs were employed to isolate processes

580 needed to reproduce the ANA teleconnection, ENSO modulation, and their impact on CONUS

581 circulation and rainfall. Whether or not the better understanding of the predictability of quasi-

582 persistent teleconnections and Rossby wave responses translates to an increase in long-range

583 rainfall forecast skill remains an open question. 
586 The authors acknowledge the National Center for Atmospheric Research for access to the

587 Community Earth System Model to conduct the prescribed SST experiments. We also thank the 588 University of Miami Institute for Data Science and Computing (IDSC) for computational 589 resources to complete the dry nonlinear AGCM model experiments. This work was supported 590 through NOAA Grants NA15OAR4320064, NA16OAR4310141, N16OAR4310149 and 591 NA20OAR430472 and DOE Grant DE-SC0019433. The authors have no competing interests to 592 declare relevant to the content of this article. 
All data analyzed in this study are described in this article, including relevant citations for accessing the data. Model data are available upon reasonable request. 
599 Becker, E., H.v. den Dool, and Q. Zhang. (2014). Predictability and Forecast Skill in NMME. J.

600 Climate, 27, 5891-5906, https://doi.org/10.1175/JCLI-D-13-00597.1.

601 Beverley, J. D., Woolnough, S. J., Baker, L. H., Johnson, S. J., \& Weisheimer, A. (2019). The

602 northern hemisphere circumglobal teleconnection in a seasonal forecast model and its

603 relationship to European summer forecast skill. Climate dynamics, 52(5), 3759-3771, 604 https://doi.org/10.1007/s00382-018-4371-4.

605 Brenner, S., Mitchell, K. (Kenneth Erwin)., Yang, C., U.S. Air Force Geophysics Laboratory.

606 Atmospheric Sciences Division. (1984). The AFGL global spectral model: expanded resolution

607 baseline version. Hanscom AFB, Massachusetts: Air Force Geophysics Laboratory, Air Force

608 Systems Command, United States Air Force. (Retrieved from

609 https://catalog.hathitrust.org/Record/102326036/Home)

610 Burgman, R. J., and Y. Jang. (2015). Simulated U.S. Drought Response to Interannual and

611 Decadal Pacific SST Variability. J. Climate, 28, 4688-4705, https://doi.org/10.1175/JCLI-D-14-

$612 \underline{00247.1 .1}$

613 Ciancarelli, B., Castro, C. L., Woodhouse, C., Dominguez, F., Chang, H. I., Carrillo, C., \&

614 Griffin, D. (2014). Dominant patterns of US warm season precipitation variability in a fine

615 resolution observational record, with focus on the southwest. International journal of

616 climatology, 34(3), 687-707, https://doi.org/10.1002/joc.3716.

617 DeAngelis, A. M., Wang, H., Koster, R. D., Schubert, S. D., Chang, Y., \& Marshak, J. (2020).

618 Prediction Skill of the 2012 U.S. Great Plains Flash Drought in Subseasonal Experiment (SubX)

619 Models, Journal of Climate, 33(14), 6229-6253, https://doi.org/10.1175/JCLI-D-19-0863.1. 
620 Ding, Q. and B. Wang. (2005). Circumglobal Teleconnection in the Northern Hemisphere

621 Summer. J. Climate, 18, 3483-3505, https://doi.org/10.1175/JCLI3473.1

622 Ding, Q., Wang, B., Wallace, J.M., and Branstator, G. (2011). Tropical-Extratropical

623 Teleconnections in Boreal Summer: Observed Interannual Variability. J. Climate 24: 1878-

624 1896. https://doi.org/10.1175/2011JCLI3621.1

625 Dirmeyer, P.A., M.J. Fennessy, and L. Marx. (2003). Low Skill in Dynamical Prediction of

626 Boreal Summer Climate: Grounds for Looking beyond Sea Surface Temperature. J. Climate, 16,

627 995-1002, https://doi.org/10.1175/1520-0442(2003)016<0995:LSIDPO>2.0.CO;2.

$628 \mathrm{Du}, \mathrm{Y} ., \mathrm{Li}, \mathrm{T} ., \mathrm{Xie}, \mathrm{Z}$. et al. (2016). Interannual variability of the Asian subtropical westerly jet

629 in boreal summer and associated with circulation and SST anomalies. Clim Dyn 46: 2673.

630 https://doi.org/10.1007/s00382-015-2723-x.

631 Ha, K. J., Seo, Y. W., Lee, J. Y., Kripalani, R. H., \& Yun, K. S. (2018). Linkages between the

632 South and East Asian summer monsoons: a review and revisit. Climate dynamics, 51(11), 4207-

633 4227, https://doi.org/10.1007/s00382-017-3773-z.

634 Hao, Z., Singh, V. P., \& Xia, Y. (2018). Seasonal drought prediction: Advances, challenges,

635 and future prospects. Reviews of Geophysics, 56, 108-

636 141. https://doi.org/10.1002/2016RG000549

637 Henderson, S. A., Maloney, E. D., \& Son, S. (2017). Madden-Julian Oscillation Pacific

638 Teleconnections: The Impact of the Basic State and MJO Representation in General Circulation

639 Models, Journal of Climate, 30(12), 4567-4587, https://doi.org/10.1175/JCLI-D-16-0789.1.

640 Hersbach, H., Bell, B., Berrisford, P., Hirahara, S., Horányi, A., Muñoz-Sabater, J., ...

641 \& Thépaut, J. N. (2020). The ERA5 global reanalysis. Quarterly Journal of the Royal

642 Meteorological Society, 146(730), 1999-2049, https://doi.org/10.1002/qj.3803. 
$643 \mathrm{Hu}, \mathrm{Q}$. and Feng, S. (2012). AMO- and ENSO-Driven Summertime Circulation and Precipitation

644 Variations in North America. J. Climate 25: 6477-6495, https://doi.org/10.1175/JCLI-D-11-

$645 \quad \underline{00520.1}$.

646 Hu, Z. Z., Kumar, A., Jha, B., \& Huang, B. (2020). How much of monthly mean precipitation

647 variability over global land is associated with SST anomalies?. Climate Dynamics, 54(1), 701-

648 712, https://doi.org/10.1007/s00382-019-05023-5.

649 Huang, B., Thorne, P.W., Banzon, V.F., Boyer, T., Chepurin, G., Lawrimore, J.H., Menne, M.J.,

650 Smith, T.M., Vose, R.S., \& Zhang, H. (2017). Extended Reconstructed Sea Surface Temperature,

651 Version 5 (ERSSTv5): Upgrades, Validations, and Intercomparisons. J. Climate 30: 8179-8205,

652 https://doi.org/10.1175/JCLI-D-16-0836.1.

653 Jha, B., Kumar, A., \& Hu, Z. Z. (2019). An update on the estimate of predictability of seasonal 654 mean atmospheric variability using North American Multi-Model Ensemble. Climate Dynamics, 655 53(12), 7397-7409. https://doi.org/10.1007/s00382-016-3217-1.

656 Jong, B., Ting, M., \& Seager, R. (2021). Assessing ENSO Summer Teleconnections, Impacts,

657 and Predictability in North America, Journal of Climate, 34(9), 3629-3643,

658 https://doi.org/10.1175/JCLI-D-20-0761.1.

659 Kim, D., Lee, S., Lopez, H., \& Goes, M. (2020). Pacific Mean-State Control of Atlantic

660 Multidecadal Oscillation-El Niño Relationship, Journal of Climate, 33(10), 4273-

661 4291, https://doi.org/10.1175/JCLI-D-19-0398.1.

662 Kirtman, B. P., D. A. Paolino, J. L. Kinter III and D. M. Straus. (2001). Impact of

663 tropical subseasonal SST variability on seasonal mean climate. Mon. Wea. Rev., 129, 853-

664 868, https://doi.org/10.1175/1520-0493(2001)129<0853:IOTSSV>2.0.CO;2. 
665 Koster, R. D., Sud, Y. C., Guo, Z., Dirmeyer, P. A., Bonan, G., Oleson, K. W., ... \& Xue, Y.

666 (2006). GLACE: the global land-atmosphere coupling experiment. Part I: overview. Journal of

667 Hydrometeorology, 7(4), 590-610, https://doi.org/10.1175/JHM510.1.

668 Lau, W., and H. Weng. (2002). Recurrent Teleconnection Patterns Linking Summertime

669 Precipitation Variability over East Asia and North America. J Meteorol. Soc. Jpn, 80, 1309-

670 1324., 10.2151/jmsj.80.1309, https://doi.org/10.2151/jmsj.80.1309.

671 Lee, J. Y., Wang, B., Ding, Q., Ha, K. J., Ahn, J. B., Kumar, A., ... \& Alves, O. (2011). How

672 predictable is the Northern Hemisphere summer upper-tropospheric circulation?. Climate

673 dynamics, 37(5), 1189-1203, https://doi.org/10.1007/s00382-010-0909-9.

674 Lee, S., Wang, B. (2016). Regional boreal summer intraseasonal oscillation over Indian Ocean

675 and Western Pacific: comparison and predictability study. Clim Dyn 46, 2213-2229,

676 https://doi.org/10.1007/s00382-015-2698-7.

677 Lee, S., Wang, C., \& Mapes, B. E. (2009). A Simple Atmospheric Model of the Local and

678 Teleconnection Responses to Tropical Heating Anomalies, Journal of Climate, 22(2), 272-284,

679 https://doi.org/10.1175/2008JCLI2303.1.

680 Li, J., Ding, R., Wu, Z., Zhong, Q., Li, B., \& Li, J. (2019). Inter-decadal change in potential

681 predictability of the East Asian summer monsoon. Theoretical and Applied Climatology, 136(1),

682 403-415, https://doi.org/10.1007/s00704-018-2482-9.

683 Liu, A.Z., M. Ting, and H. Wang. (1998). Maintenance of Circulation Anomalies during the

6841988 Drought and 1993 Floods over the United States. J. Atmos. Sci., 55, 2810-2832,

685 https://doi.org/10.1175/1520-0469(1998)055<2810:MOCADT>2.0.CO;2. 
Liu, F., Li, T., Wang, H., Deng, L., \& Zhang, Y. (2016). Modulation of Boreal

687 Summer Intraseasonal Oscillations over the Western North Pacific by ENSO, Journal of Climate, 29(20), 7189-7201, https://doi.org/10.1175/JCLI-D-15-0831.1.

689 Liu, Y., Ke, Z., \& Ding, Y. (2019). Predictability of East Asian summer monsoon in seasonal 690 climate forecast models. International Journal of Climatology, 39(15), 5688-5701,

691 https://doi.org/10.1002/joc.6180.

692 Lopez, H., Lee, S.-K., Dong, S., Goni, G., Kirtman, B., Atlas, R., \& Kumar, A. (2019). East

693 Asian Monsoon as a modulator of U.S. Great Plains heatwaves. Journal of Geophysical Research

694 : Atmospheres, 124, 6342-6358. https://doi.org/10.1029/2018JD030151.

695 Mallakpour, I., Villarini, G. (2016). Investigating the relationship between the frequency of

696 flooding over the central United States and large-scale climate, Advances in Water Resources 92:

697 159-171, https://doi.org/10.1016/j.advwatres.2016.04.008.

698 Malloy, K. M., \& Kirtman, B. P. (2020). Predictability of Midsummer Great Plains Low-Level

699 Jet and Associated Precipitation, Weather and Forecasting, 35(1), 215-235,

$700 \quad$ https://doi.org/10.1175/WAF-D-19-0103.1.

701 Mariotti, A., Baggett, C., Barnes, E. A., Becker, E., Butler, A., Collins, D. C., Dirmeyer, P. A., 702 Ferranti, L., Johnson, N. C., Jones, J., Kirtman, B. P., Lang, A. L., Molod, A., Newman, M., 703 Robertson, A. W., Schubert, S., Waliser, D. E., \& Albers, J. (2020). Windows of Opportunity for 704 Skillful Forecasts Subseasonal to Seasonal and Beyond, Bulletin of the American Meteorological 705 Society, 101(5), E608-E625, 2021, https://doi.org/10.1175/BAMS-D-18-0326.1.

706 Moon, J. Y., Wang, B., Ha, K. J., \& Lee, J. Y. (2013). Teleconnections associated with Northern 707 Hemisphere summer monsoon intraseasonal oscillation. Climate dynamics, 40(11-12), 2761708 2774, https://doi.org/10.1007/s00382-012-1394-0. 
709 Neale RB et al. (2010). Description of the NCAR Community Atmosphere Model (CAM 5.0).

710 NCAR technical note NCAR/TN-486+STR, National Center for Atmospheric Research,

711 Boulder.

712 O'Reilly, C.H., Woollings, T., Zanna, L., and Weisheimer, A. (2018). The Impact of Tropical

713 Precipitation on Summertime Euro-Atlantic Circulation via a Circumglobal Wave Train. J.

714 Climate 31: 6481-6504. https://doi.org/10.1175/JCLI-D-17-0451.1.

715 Pegion, P. J., and A. Kumar. (2010). Multimodel Estimates of Atmospheric Response to Modes

716 of SST Variability and Implications for Droughts. J. Climate, 23, 4327-4341,

717 https://doi.org/10.1175/2010JCLI3295.1.

718 Slater, L. J., G. Villarini, and A. A. Bradley. (2016). Evaluation of the skill of North-American

719 Multi-Model Ensemble (NMME) global climate models in predicting average and extreme

720 precipitation and temperature over the continental USA. Climate Dyn.,

721 https://doi.org/10.1007/s00382-016-3286-1.

722 Schubert, S.D., M.J. Suarez, P.J. Pegion, M.A. Kistler, and A. Kumar. (2002). Predictability of

723 Zonal Means during Boreal Summer. J. Climate, 15, 420-434, https://doi.org/10.1175/1520-

$724 \quad$ 0442(2002)015<0420:POZMDB >2.0.CO;2.

725 Schubert, S. D., Suarez, M. J., Pegion, P. J., Koster, R. D., \& Bacmeister, J. T. (2008). Potential

726 Predictability of Long-Term Drought and Pluvial Conditions in the U.S. Great Plains, Journal of

727 Climate, 21(4), 802-816, https://doi.org/10.1175/2007JCLI1741.1.

728 Schubert, S., H. Wang, and M. Suarez/ (2011). Warm Season Subseasonal Variability and

729 Climate Extremes in the Northern Hemisphere: The Role of Stationary Rossby Waves. J.

730 Climate, 24, 4773-4792, https://doi.org/10.1175/JCLI-D-10-05035.1. 
731 Sheffield, J., S.J. Camargo, R. Fu, Q. Hu, X. Jiang, N. Johnson, K.B. Karnauskas, S.T. Kim, J.

732 Kinter, S. Kumar, B. Langenbrunner, E. Maloney, A. Mariotti, J.E. Meyerson, J.D. Neelin, S.

733 Nigam, Z. Pan, A. Ruiz-Barradas, R. Seager, Y.L. Serra, D. Sun, C. Wang, S. Xie, J. Yu, T.

734 Zhang, and M. Zhao. (2013). North American Climate in CMIP5 Experiments. Part II:

735 Evaluation of Historical Simulations of Intraseasonal to Decadal Variability. J. Climate 26:

736 9247-9290, https://doi.org/10.1175/JCLI-D-12-00593.1.

737 Song, F., \& Zhou, T. (2015). The crucial role of internal variability in modulating the decadal

738 variation of the East Asian summer monsoon-ENSO relationship during the twentieth century.

739 Journal of Climate, 28(18), 7093-7107, https://doi.org/10.1175/JCLI-D-14-00783.1.

740 Sperber, K. R., Annamalai, H., Kang, I. S., Kitoh, A., Moise, A., Turner, A., ... \& Zhou, T.

741 (2013). The Asian summer monsoon: an intercomparison of CMIP5 vs. CMIP3 simulations of

742 the late 20th century. Climate dynamics, 41(9-10), 2711-2744, https://doi.org/10.1007/s00382-

$743 \quad \underline{012-1607-6 .}$

744 Tian, D., Wood, E. F., \& Yuan, X. (2017). CFSv2-based sub-seasonal precipitation and

745 temperature forecast skill over the contiguous United States. Hydrology and Earth System

746 Sciences, 21(3), 1477-1490, https://doi.org/10.5194/hess-21-1477-2017.

747 Ting, M. and Wang, H. (1997). Summertime U.S. Precipitation Variability and Its Relation to

748 Pacific Sea Surface Temperature. J. Climate 10: 1853-1873, https://doi.org/10.1175/1520-

$749 \quad$ 0442(1997)010<1853:SUSPVA>2.0.CO;2.

750 Trenberth, K. E., Branstator, G.W., Karoly, D., Kumar, A., Lau, N.C-. \& Ropelewski C. (1998).

751 Progress during TOGA in understanding and modeling global teleconnections associated with

752 tropical sea surface temperatures, J. Geophys. Res. 103(C7): 14291-14324,

753 https://doi.org/10.1029/97JC01444. 
754 Islam, S., \& Tang, Y. (2017). Simulation of different types of ENSO impacts on South Asian

755 Monsoon in CCSM4. Climate Dynamics, 48(3-4), 893-911, https://doi.org/10.1007/s00382-016-

$756 \quad \underline{3117-4}$.

757 Islam, S., Tang, Y., \& Jackson, P. L. (2013). Asian monsoon simulations by Community Climate

758 Models CAM4 and CCSM4. Climate dynamics, 41(9-10), 2617-2642, 0.1007/s00382-013-1752-

7596.

760 Wang, J., Kim, H., Kim, D., Henderson, S. A., Stan, C., \& Maloney, E. D. (2020). MJO

761 Teleconnections over the PNA Region in Climate Models. Part II: Impacts of the MJO and Basic

762 State, Journal of Climate, 33(12), 5081-5101, https://doi.org/10.1175/JCLI-D-19-0865.1.

763 Wang, B., R. Wu, and K. Lau. (2001). Interannual Variability of the Asian Summer Monsoon:

764 Contrasts between the Indian and the Western North Pacific-East Asian Monsoons. J. Climate, 765 14, 4073-4090, https://doi.org/10.1175/1520-0442(2001)014<4073:IVOTAS>2.0.CO;2.

766 Wang, B., Wu, Z., Li, J., Liu, J., Chang, C. P., Ding, Y., \& Wu, G. (2008). How to measure the 767 strength of the East Asian summer monsoon. Journal of Climate, 21(17), 4449-

768 4463, https://doi.org/10.1175/2008JCLI2183.1.

769 Weaver, S.J., Schubert, S., \& Wang, H. (2009). Warm Season Variations in the Low-Level

770 Circulation and Precipitation over the Central United States in Observations, AMIP Simulations,

771 and Idealized SST Experiments. J. Climate 22: 5401-5420,

772 https://doi.org/10.1175/2009JCLI2984.1.

773 Weaver, S.J., Baxter, S., and Harnos, K. (2016). Regional Changes in the Interannual Variability 774 of U.S. Warm Season Precipitation. J. Climate 29: 5157-5173, https://doi.org/10.1175/JCLI-D$775 \quad$ 14-00803.1. 
776 Wu, B., Zhou, T., \& Li, T. (2009). Contrast of Rainfall-SST Relationships in the Western North

777 Pacific between the ENSO-Developing and ENSO-Decaying Summers, Journal of Climate,

778 22(16), 4398-4405, https://doi.org/10.1175/2009JCLI2648.1.

779 Xie, P., \& Arkin, P. A. (1997). Global precipitation: A 17-year monthly analysis based on gauge

780 observations, satellite estimates, and numerical model outputs. Bulletin of

781 the american meteorological society, 78(11), 2539-2558, https://doi.org/10.1175/1520-

$782 \quad$ 0477(1997)078<2539:GPAYMA >2.0.CO;2.

783 Yang, Y., Zhu, Z., Li, T., \& Yao, M. (2020). Effects of western Pacific intraseasonal convection 784 on surface air temperature anomalies over North America. International Journal of Climatology, 785 40(6), 2913-2923, https://doi.org/10.1002/joc.6373.

786 Zhao, G., Huang, G., Wu, R., Tao, W., Gong, H., Qu, X., \& Hu, K. (2015). A New Upper-Level 787 Circulation Index for the East Asian Summer Monsoon Variability, Journal of Climate, 28(24), 788 9977-9996, https://doi.org/10.1175/JCLI-D-15-0272.1.

789 Zhao, S., Y. Deng, and R.X. Black. (2018). An Intraseasonal Mode of Atmospheric Variability

790 Relevant to the U.S. Hydroclimate in Boreal Summer: Dynamic Origin and East Asia

791 Connection. J. Climate, 31, 9855-9868, https://doi.org/10.1175/JCLI-D-18-0206.1.

792 Zhou, F., Ren, H. L., Hu, Z. Z., Liu, M. H., Wu, J., \& Liu, C. Z. (2020). Seasonal predictability

793 of primary East Asian summer circulation patterns by three operational climate prediction

794 models. Quarterly Journal of the Royal Meteorological Society, 146(727), 629-646,

795 https://doi.org/10.1002/qj.3697.

796 Zhou, S., L'Heureux, M., Weaver, S. et al. (2012). A composite study of the MJO influence on 797 the surface air temperature and precipitation over the Continental United States. Clim Dyn 38, 798 1459-1471, https://doi.org/10.1007/s00382-011-1001-9. 
799 Zhu, J., Huang, B., Hu, Z. Z., Kinter, J. L., \& Marx, L. (2013). Predicting US summer

800 precipitation using NCEP Climate Forecast System version 2 initialized by multiple ocean

801 analyses. Climate dynamics, 41(7-8), 1941-1954, https://doi.org/10.1007/s00382-013-1785-x.

802 Zhu, Z. and T. Li. (2016). A New Paradigm for Continental U.S. Summer Rainfall Variability:

803 Asia-North America Teleconnection. J. Climate, 29, 7313-7327, https://doi.org/10.1175/JCLI-

804 D-16-0137.1.

805 Zhu, Z. and T. Li. (2018). Amplified contiguous United States summer rainfall variability

806 induced by East Asian monsoon interdecadal change. Clim Dyn 50: 3523.

807 https://doi.org/10.1007/s00382-017-3821-8.

808

809 


\section{Figures}
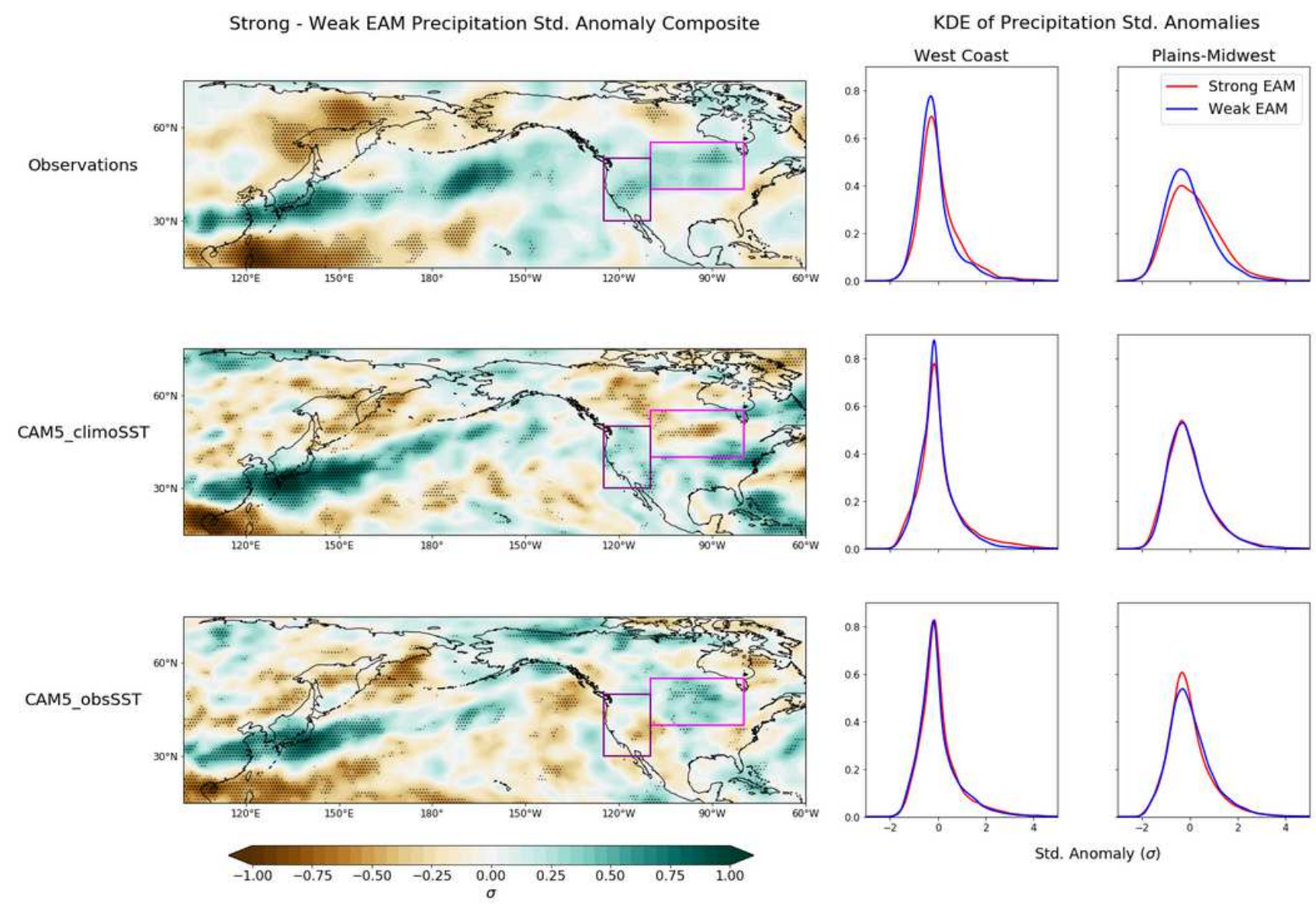

\section{Figure 1}

(left column) Strong - weak EAM precipitation standardized anomaly composites for (top) CMAP observations, (middle) CAM5_climoSST, the CAM5 experiment with prescribed climatological SSTs, and (bottom) CAM5_obsSST, the CAM5 experiment with prescribed observed SSTs. Stippling indicates anomalies significant at the $90 \%$ confidence level. Purple and magenta boxes denote West Coast and Plains-Midwest domains, respectively. (middle and right columns) Kernel density estimators of the precipitation standardized anomalies for the grid points corresponding to the (middle) West Coast and (right) Plains-Midwest domains for (red solid) strong EAM months and (blue solid) weak EAM months. 


\section{Strong - Weak EAM $\overline{Z 250^{\prime}} *$}
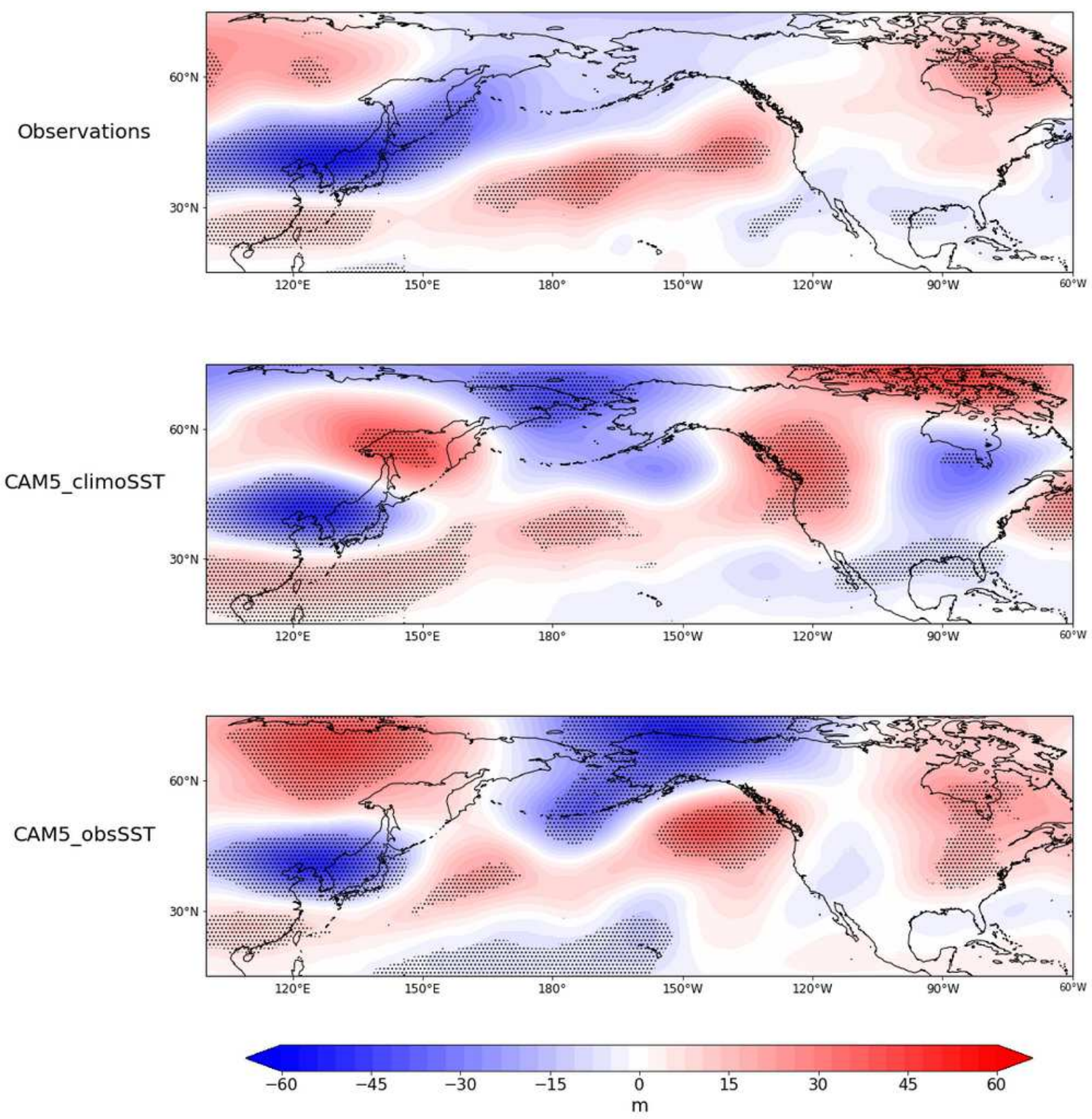

\section{Figure 2}

Zonally-asymmetric component of strong - weak EAM Z250 anomaly composites for (top) ERA5 observations, (middle) CAM5_climoSST experiment, and (bottom) CAM5_obsSST experiment. 

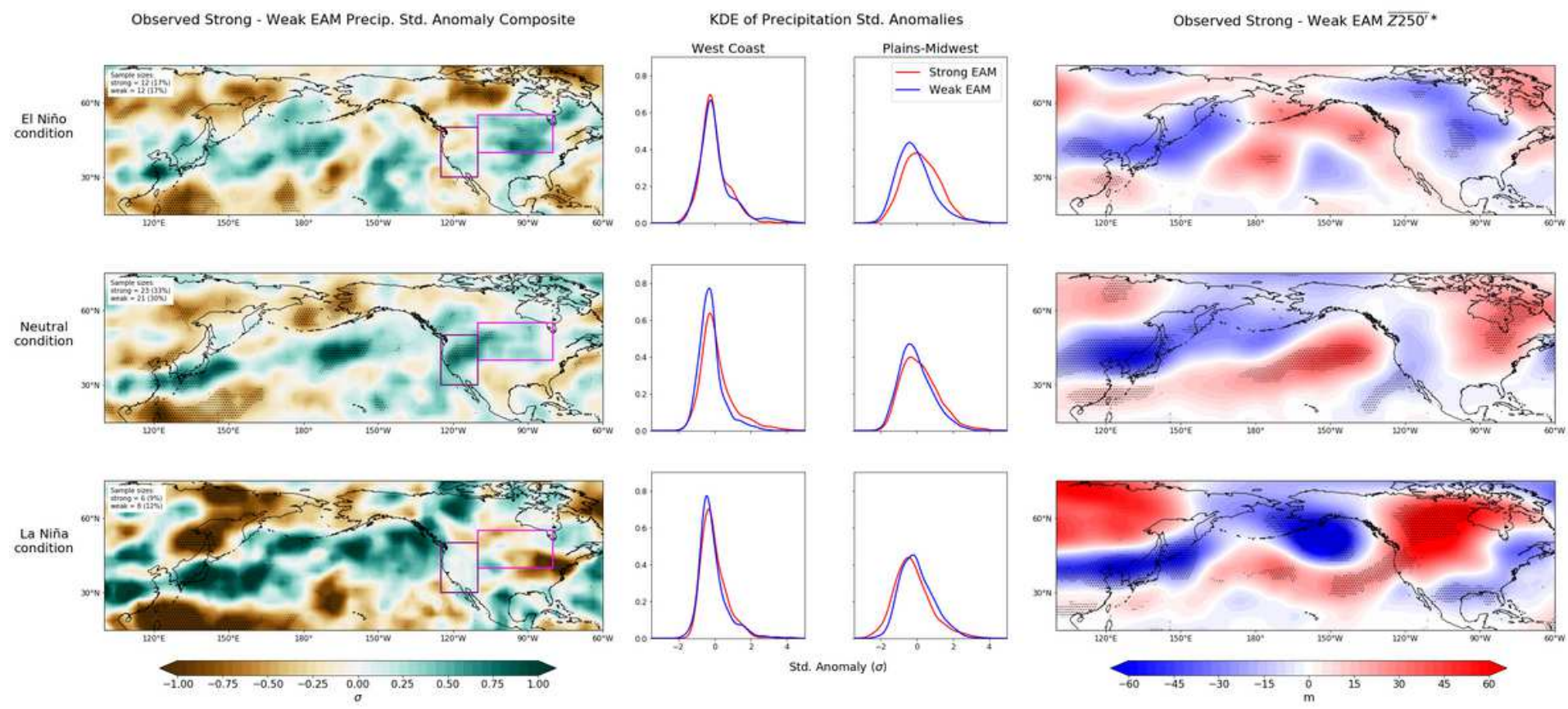

\section{Figure 3}

(left column) Observed strong - weak EAM precipitation standardized anomaly composites during (top) El Niño conditions, (middle) neutral ENSO conditions, and (bottom) La Niña conditions. Purple and magenta boxes denote West Coast and Plains-Midwest domains, respectively. Stippling indicates anomalies significant at the $90 \%$ confidence level. Sample sizes for composites are also annotated in upper-left corner. (middle columns) Kernel density estimators of the precipitation standardized anomalies for the grid points corresponding to the (middle-left) West Coast and (middle-right) Plains-Midwest domains for (red) strong EAM months and (blue) weak EAM months. (right column) Observed zonallyasymmetric component of strong - weak EAM Z250 composites during (top) El Niño conditions, (middle) neutral ENSO conditions, and (bottom) La Niña conditions. 

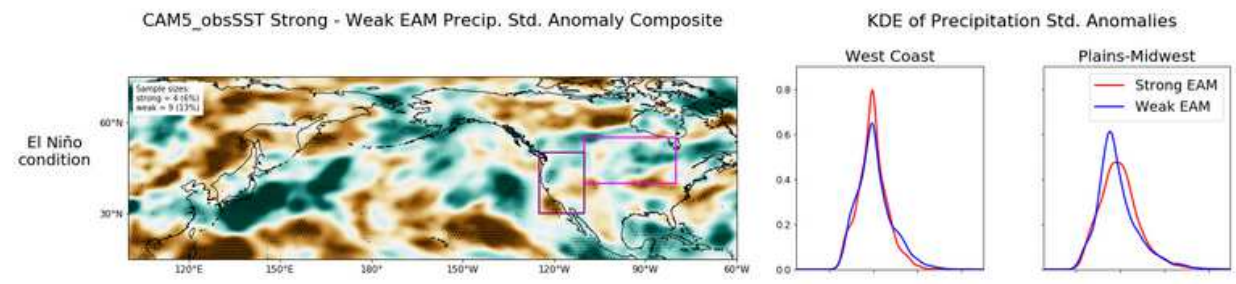

CAM5_obsSST Strong - Weak EAM $\overline{Z 250^{\prime}}$.
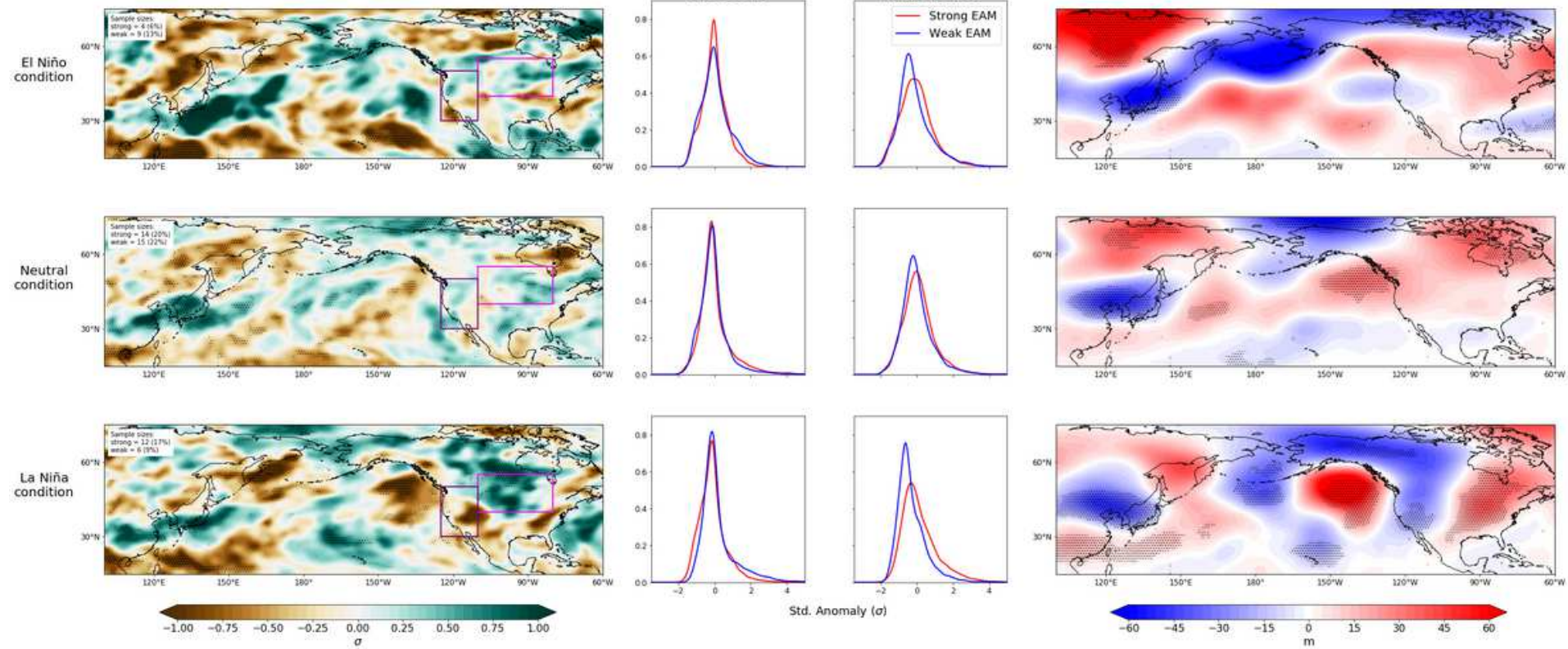

Figure 4

Same as Fig. 3, but for CAM5_obsSST experiment.

Steady-state linear QG solutions of EAM-forced Z250 anomalies
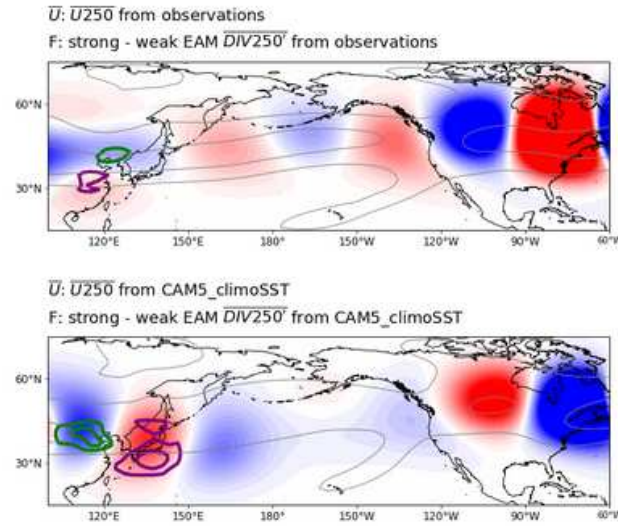

$\bar{U}: \overline{U 250}$ from CAMS_climossT

F: strong - weak EAM DIV250 from observations

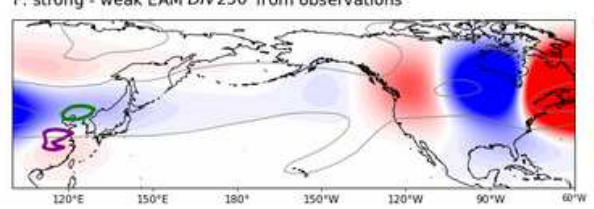

$\bar{U}: \bar{U} 250$ from observations
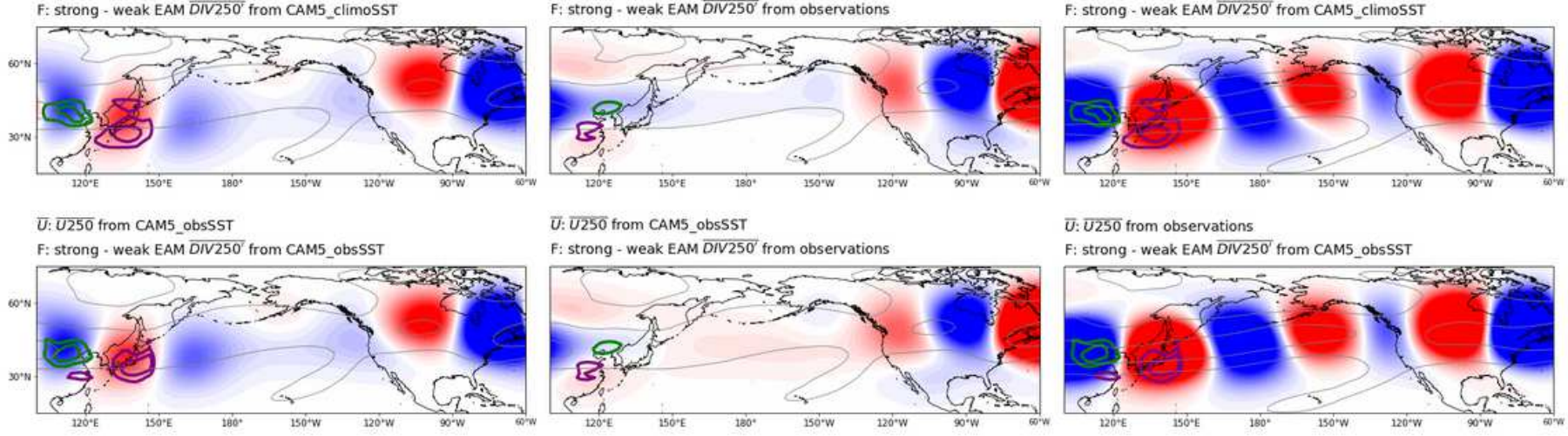

$\bar{U}: \overline{U 250}$ from CAMS_obsSST

F: strong - weak EAM $\overline{D I V 250}$ from observations

$\bar{U}: \overline{U 250}$ from observations

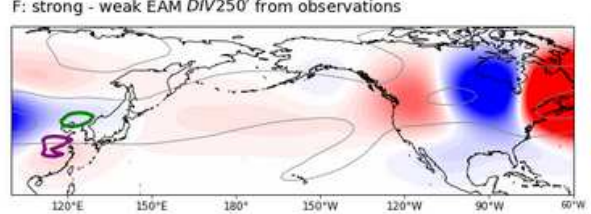

F: strong - weak EAM $\overline{D I V 250}$ from CAM5_obsSST

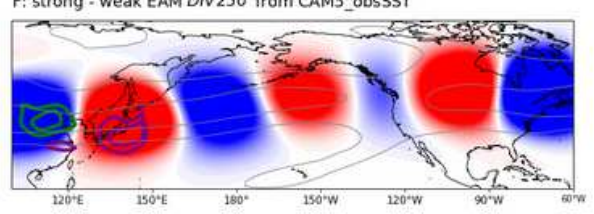

\section{Figure 5}

Linear steady-state QG solutions of Z250 with Ū and F from (left column) (top) observations, (middle) CAM5_climoSST experiment, and (bottom) CAM5_obsSST experiment. (middle column) Solutions of 
Z250 with F from observations and Ū from (top) CAM5_climoSST experiment and (bottom) CAM5_obsSST experiment. (right column) Solutions of Z250 with Ū from observations and F from (top) CAM5_climoSST experiment and (bottom) CAM5_obsSST experiment. The corresponding Ū is overlaid in light gray with contours of 10 and $20 \mathrm{~m} \mathrm{~s}-1$. The corresponding $F$ is overlaid, with thick green contours as -0.5 and -1 s- $1 \times 10-6$ and thick purple contours as 0.5 and $1 \mathrm{~s}-1 \times 10-6$.

Steady-state linear QG solutions of EAM-forced Z250 anomalies with F conditioned on ENSO
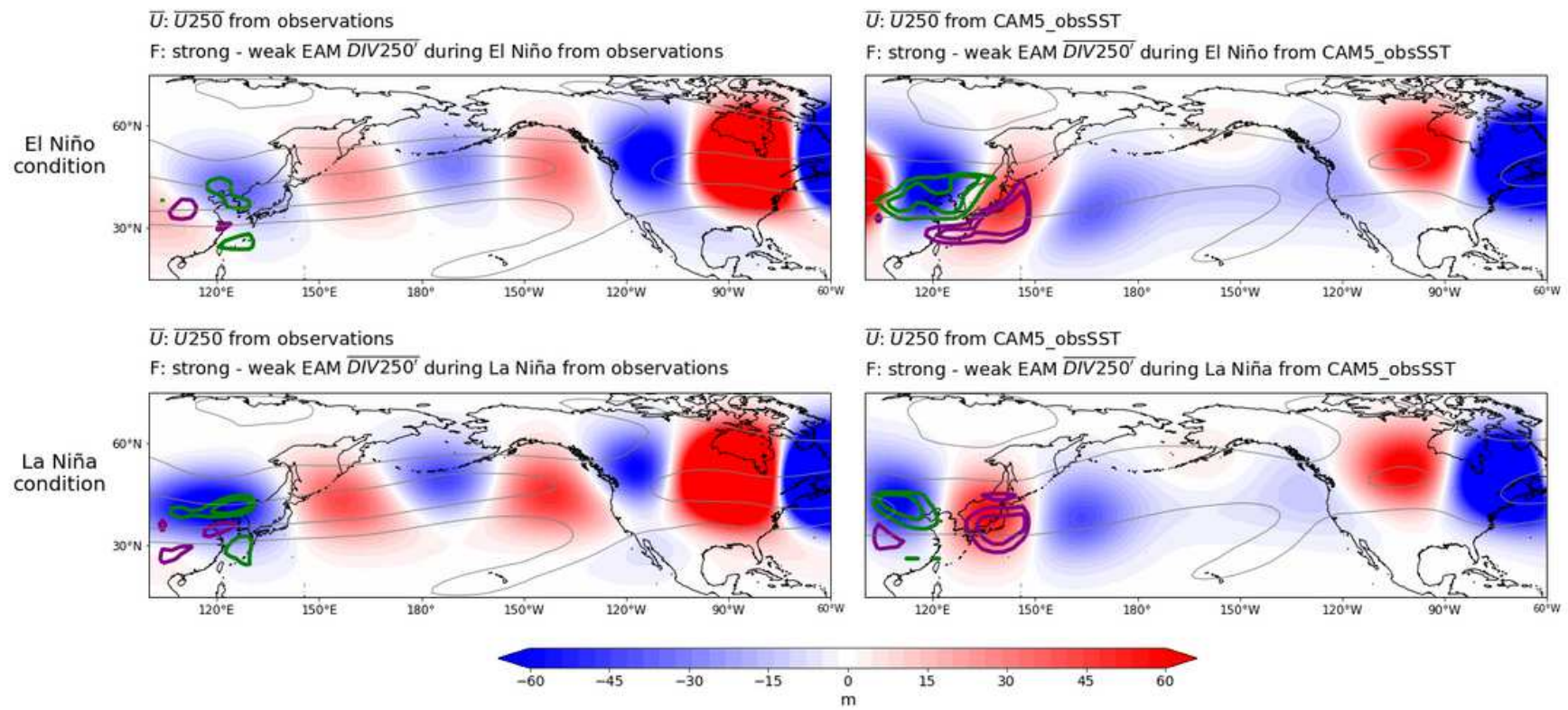

Figure 6

Linear steady-state QG solutions of Z250 with $\bar{U}$ and $F$ from (left column) observations and (right column) CAM5_climoSST experiment. (top row) Solutions when F is conditioned on El Niño, and (bottom row) solutions when $\mathrm{F}$ is conditioned on La Niña. The corresponding $\bar{U}$ is overlaid in light gray with contours of 10 and $20 \mathrm{~m} \mathrm{~s}-1$. The corresponding $F$ is overlaid, with thick green contours as -0.5 and $-1 \mathrm{~s}-1$ $\mathrm{x} 10-6$ and thick purple contours as 0.5 and $1 \mathrm{~s}-1$ x $10-6$. 


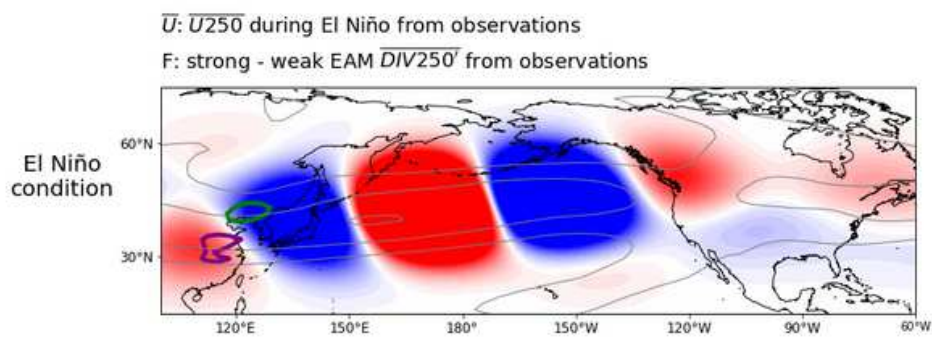

$\bar{U}: \overline{U 250}$ during El Niño from CAM5_obsSST

F: strong - weak EAM $\overline{D^{\prime} / V 250^{\prime}}$ from CAM5_obsSST

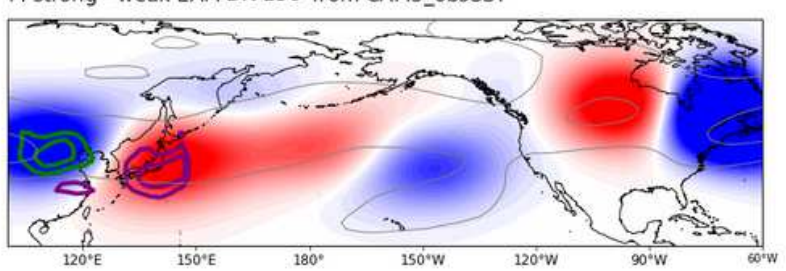

U: $\overline{U 250}$ during La Niña from observations

F: strong - weak EAM $\overline{D I V 250^{\prime}}$ from observations

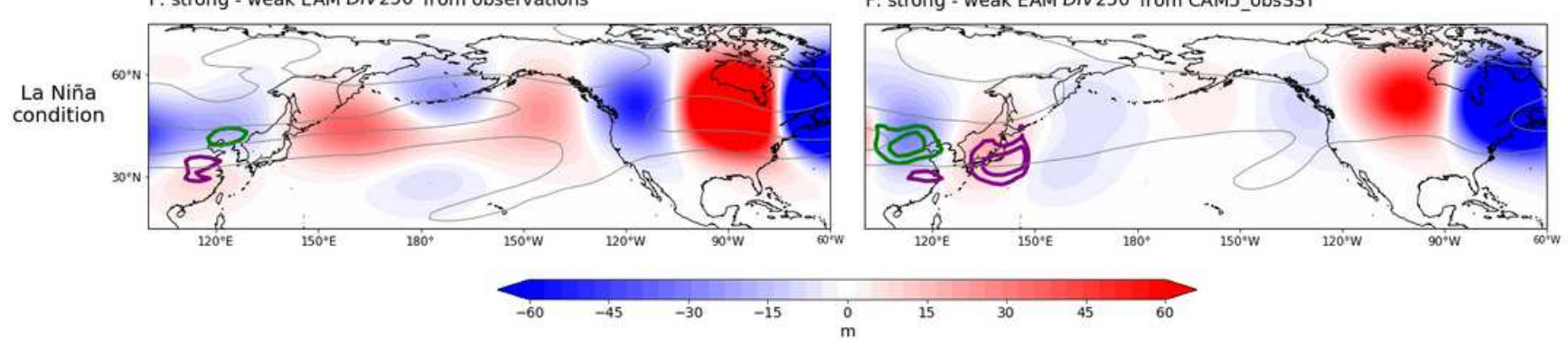

Figure 7

Same as Fig. 6, but when Ū is conditioned on (top row) El Niño and (bottom row) La Niña.

ENSO-modulated part of linear QG solutions of Z250 anomalies

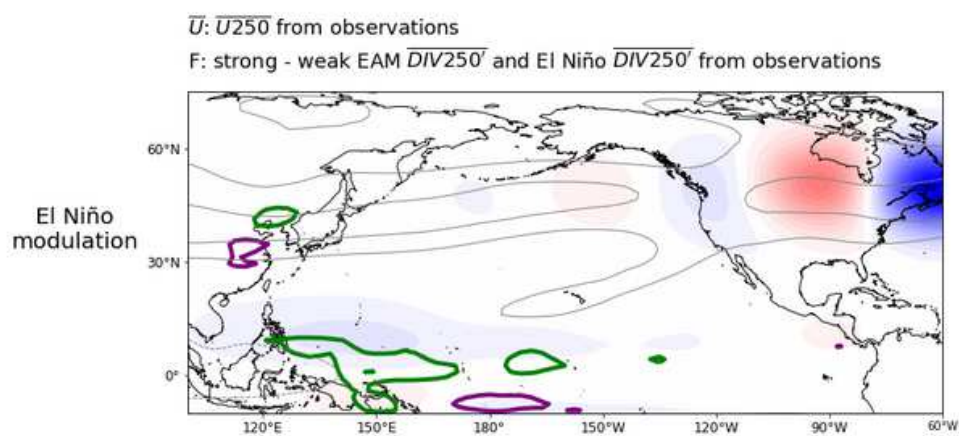

U: $\overline{U 250}$ from CAM5_obsSST

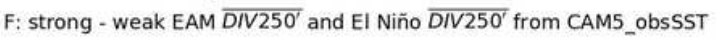

$\bar{U}: \overline{U 250}$ from observations

F: strong - weak EAM $\overline{D I V 250^{\prime}}$ and La Niña $\overline{D I V 250^{\prime}}$ from observations

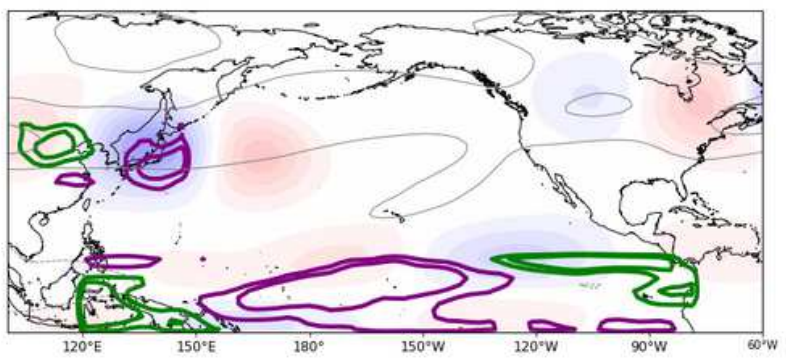

$\bar{U}: \overline{U 250}$ from CAM5_obsSST

F: strong - weak EAM $\overline{D_{I V 2} 250^{\prime}}$ and La Niña $\overline{D^{\prime} / 250^{\prime}}$ from CAM5_obsSST

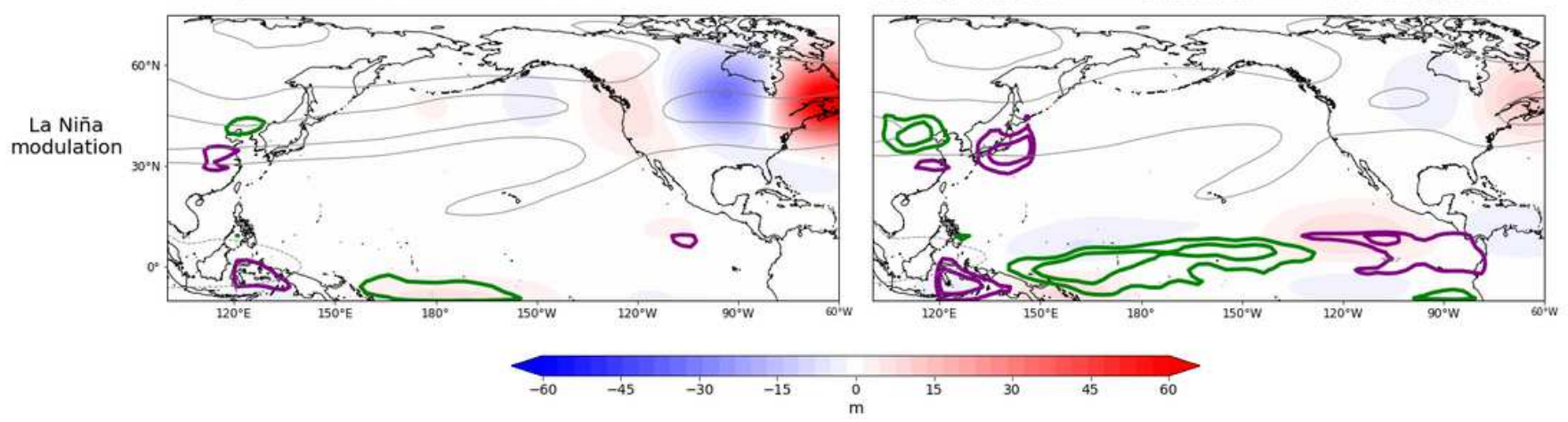

Figure 8 
ENSO-modulated part of the steady-state linear QG solutions with Ū and F from (left column) observations and (right column) CAM5_climoSST experiment. (top row) Solutions when F includes El Niño-related divergence anomalies, and (bottom row) solutions when F includes La Niña-related divergence anomalies. The corresponding $\bar{U}$ is overlaid in light gray with contours of 10 and $20 \mathrm{~m} \mathrm{~s}-1$. The corresponding $F$ is overlaid, with thick green contours as -0.5 and -1 s $-1 \times 10-6$ and thick purple contours as 0.5 and $1 \mathrm{~s}-1 \times 10-6$.

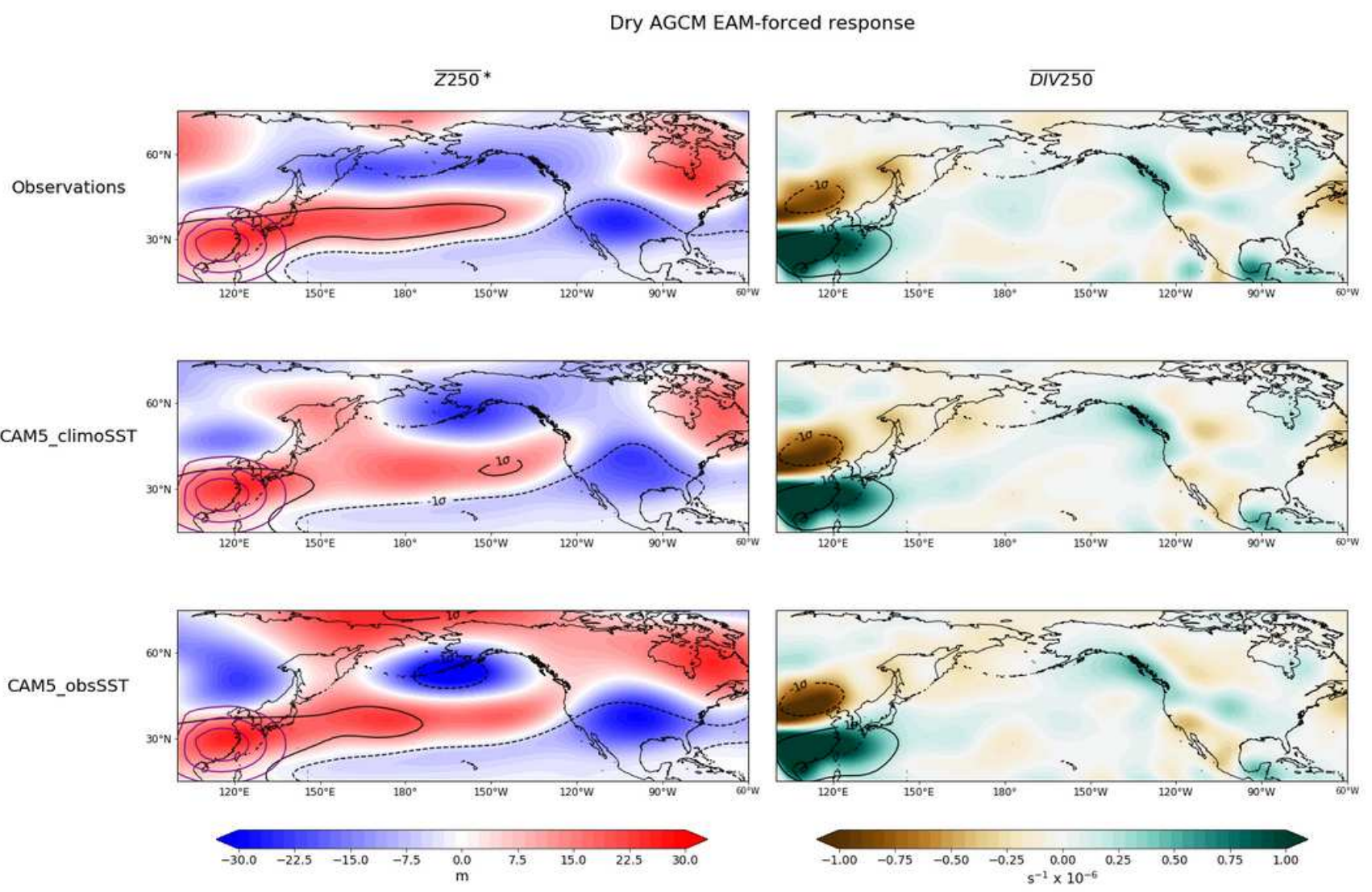

Figure 9

Dry AGCM EAM heating response, including the (left column) asymmetric component of the time-mean Z250 and (right column) time-mean DIV250, for when the inputted mean state is from (top row) observations, (middle row) CAM5_climoSST experiment, and (bottom row) CAM5_obsSST experiment. The $1 \sigma$ (solid black) and $-1 \sigma$ (dashed black) values - calculated by dividing response by divided by the 90-day moving mean $\sigma-$ are overlaid, representing $\sim 67 \%$ of the variability of the response assuming Gaussian statistics. Heating forcing (purple contours) of $0.5,1$, and $1.5 \mathrm{~K}$ day-1 are also overlaid on Z250 responses. 
$\overline{Z 250 *}$
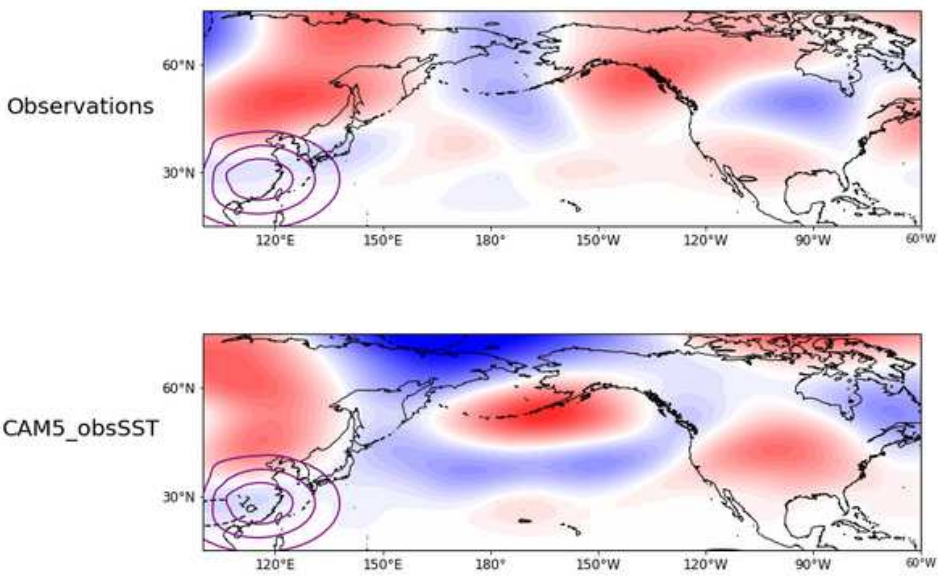

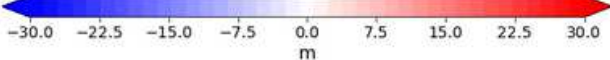

$\overline{D I V 250}$
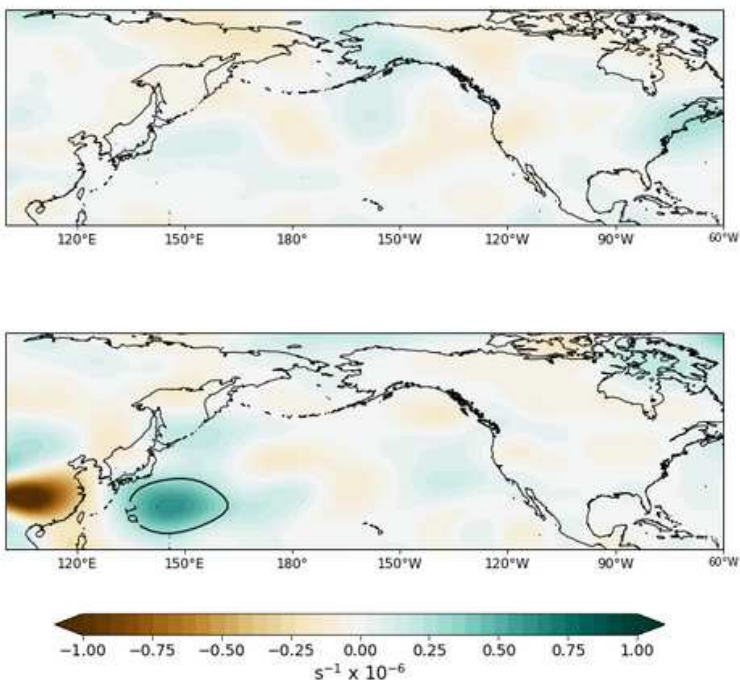

Figure 10

Difference in dry AGCM EAM heating response from Fig. 9, including the (left column) asymmetric component of the time-mean Z250 and (right column) time-mean DIV250, for when the inputted mean state is taken during El Niño from (top row) observations and (bottom row) CAM5_obsSST experiment. The $1 \sigma$ (solid black) and $-1 \sigma$ (dashed black) values are overlaid. Heating forcing (purple contours) are the same as Fig. 9.

Difference in EAM-forced response when mean state conditioned on La Niña
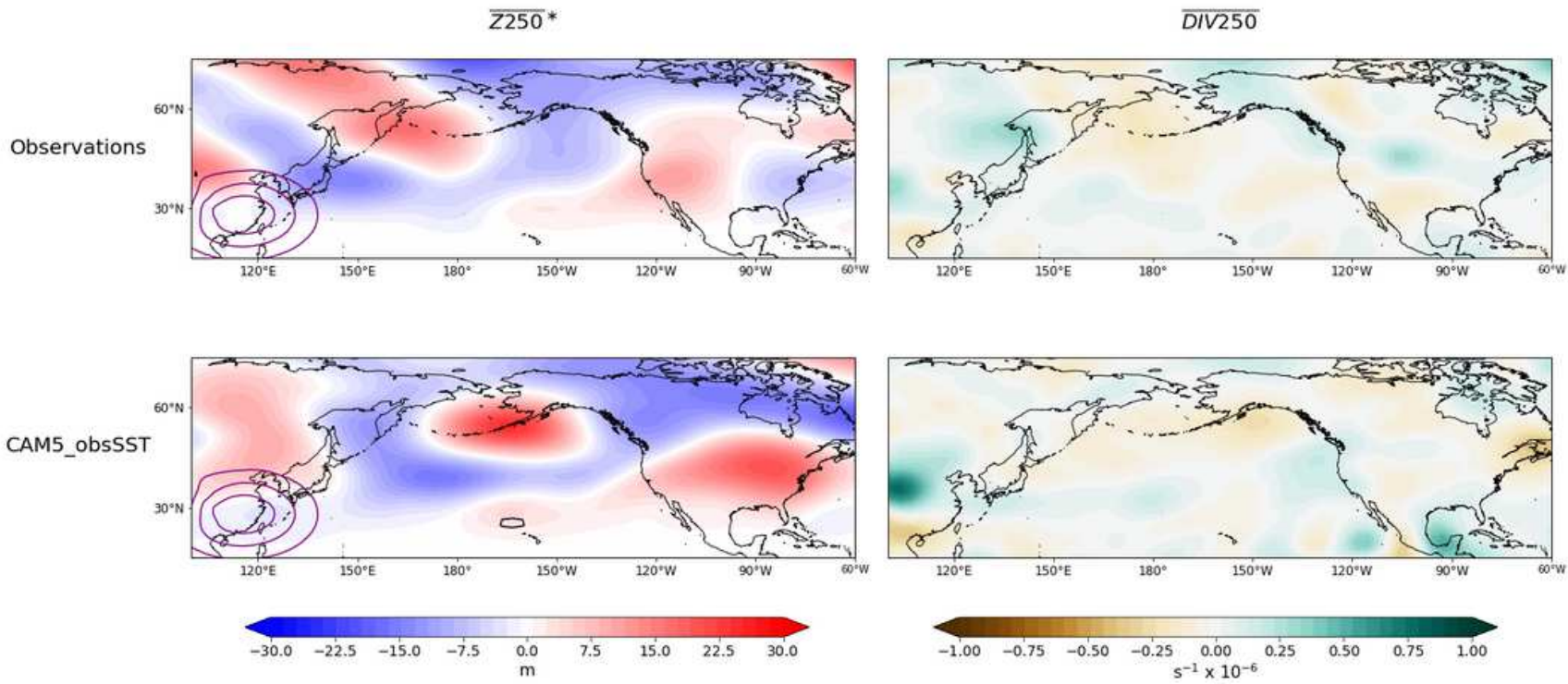

\section{Figure 11}

Same as Fig. 10, but for mean state taken during La Niña. 
$\overline{Z 250 *}$
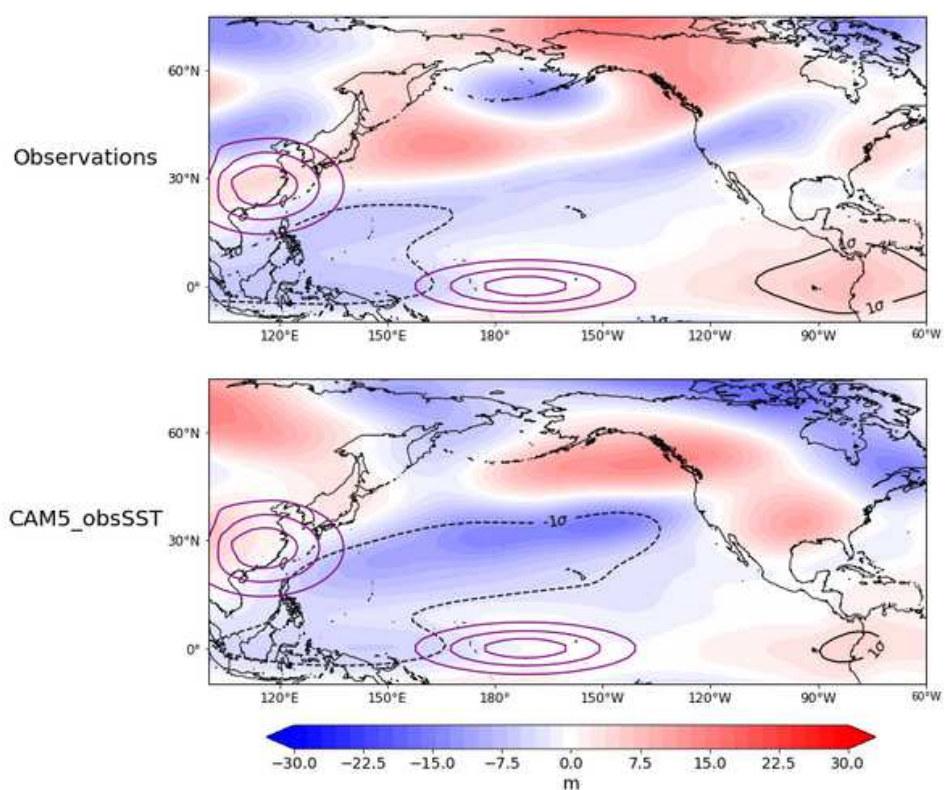

$\overline{\operatorname{DI} 250}$
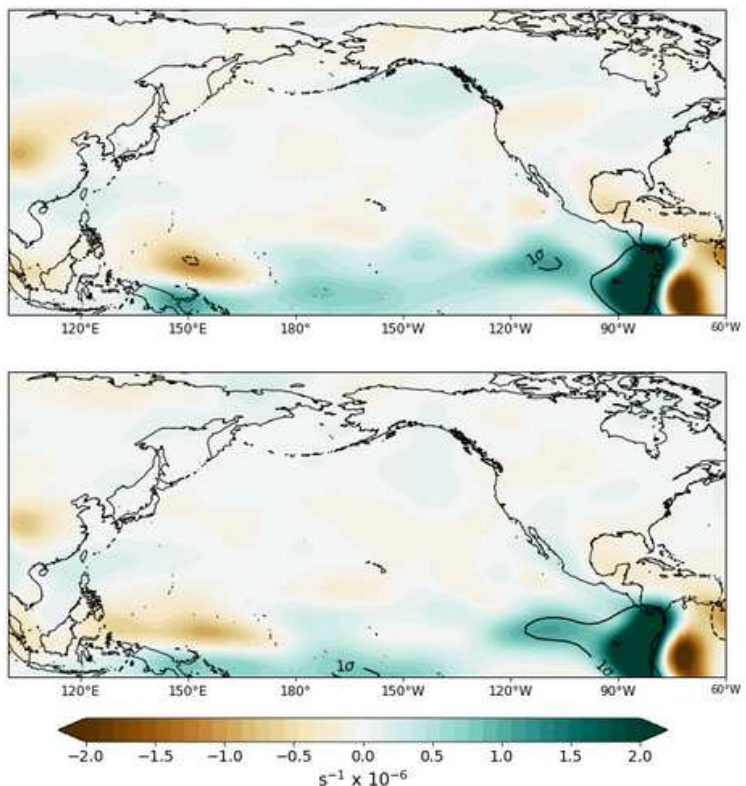

Figure 12

Dry AGCM EI Niño-modulated part of the heating response (see Table 1 for details). (left column) asymmetric component of the time-mean Z250 and (right column) time-mean DIV250, for when the inputted mean state is taken from (top row) observations and (bottom row) CAM5_obsSST experiment. The $1 \sigma$ (solid black) and $-1 \sigma$ (dashed black) values are overlaid. Heating forcing (purple contours) of 0.5 , 1 , and $1.5 \mathrm{~K}$ day-1 from combined EAM- and El Niño-forced experiment are also overlaid on Z250 responses.

Dry AGCM La Niña-modulated part of response
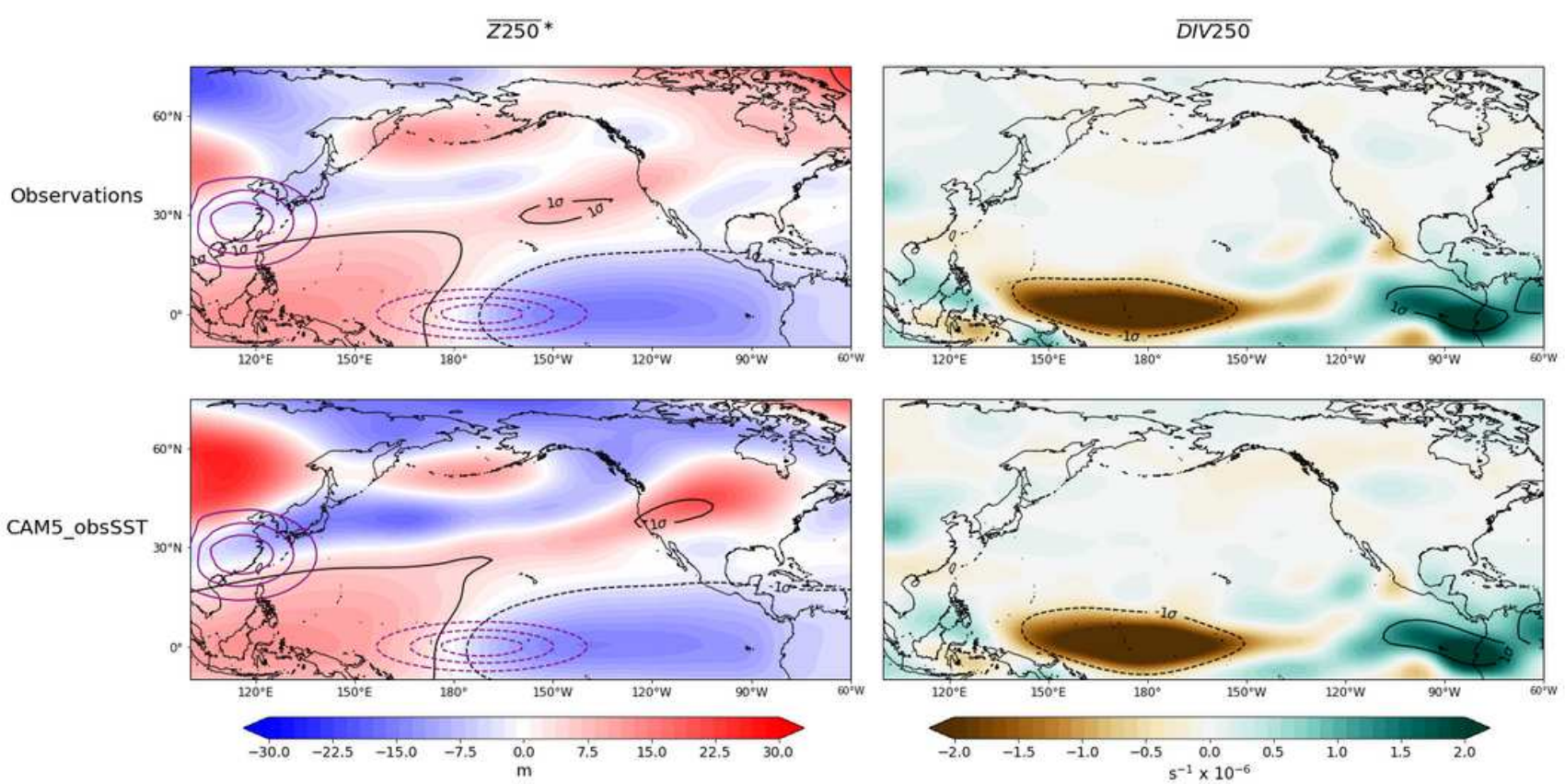
Figure 13

Same as Fig. 12, but the La Niña-modulated part of the heating response. Heating forcing (purple contours) of $-0.5,-1$, and $-1.5 \mathrm{~K}$ day- 1 are included. 